\title{
Comparison of Skeletal and Dentoalveolar Changes between Two Bone-Borne Maxillary Expanders
}

mohamad sarraj

ms0108@mix.wvu.edu

Follow this and additional works at: https://researchrepository.wvu.edu/etd

Part of the Orthodontics and Orthodontology Commons

\section{Recommended Citation}

sarraj, mohamad, "Comparison of Skeletal and Dentoalveolar Changes between Two Bone-Borne Maxillary Expanders" (2020). Graduate Theses, Dissertations, and Problem Reports. 7786.

https://researchrepository.wvu.edu/etd/7786

This Thesis is protected by copyright and/or related rights. It has been brought to you by the The Research Repository @ WVU with permission from the rights-holder(s). You are free to use this Thesis in any way that is permitted by the copyright and related rights legislation that applies to your use. For other uses you must obtain permission from the rights-holder(s) directly, unless additional rights are indicated by a Creative Commons license in the record and/ or on the work itself. This Thesis has been accepted for inclusion in WVU Graduate Theses, Dissertations, and Problem Reports collection by an authorized administrator of The Research Repository @ WVU. For more information, please contact researchrepository@mail.wvu.edu. 


\title{
Comparison of Skeletal and Dentoalveolar Changes between Two Bone-Borne Maxillary Expanders
}

\author{
Mohamad Sarraj, D.D.S.
}

Thesis submitted to the School of Dentistry

at West Virginia University

In partial fulfillment of the requirements for the degree of

Master of Science in Orthodontics

\author{
Peter Ngan, D.M.D., M.S., Chair \\ Christina DeBiase, M.A., Ed.D. \\ Chris Martin, D.D.S., M.S. \\ Department of Orthodontics
}

\section{Morgantown, West Virginia \\ 2020}

Keywords: Rapid palatal expansion, CBCT, Bone-borne expander, MARPE, Micro-implant.

Copyright 2020 Mohamad Sarraj, D.D.S. 


\title{
ABSTRACT \\ Comparison of Skeletal and Dentoalveolar Changes between Two Bone-Borne Maxillary Expanders
}

\author{
Mohamad Sarraj, D.D.S.
}

Introduction: Bone-borne maxillary expander (BBME) are designed to provide additional anchorage to widen the maxillary arch for patients who exhibit maxillary transverse deficiency. One form of BBME is the hybrid BBME which uses mini-implants (bone-borne) and posterior teeth (tooth-borne) as anchorage for maxillary expansion. The other form of BBME is absolute BBME which only uses mini-implants as anchorage. It is not clear in the literature if there is a difference in skeletal and dental changes with these two types of expanders. The objective of this study was to compare the skeletal, dentoalveolar, and periodontal changes between the hybrid and the absolute BBME using cone-beam computed tomography (CBCT).

Materials and Methods: Thirty four adolescent patients with transverse maxillary deficiency were divided into two groups; the first group (16 patients) was treated with the hybrid BBME, and the second group (18 patients) was treated with absolute BBME. CBCT scans were taken pre-treatment (T1); and immediately post-expansion (T2) to measure the changes in midpalatal suture opening, total expansion (TE), alveolar bone bending (ABB), dental tipping (DT), and buccal bone thickness (BBT) at the first molar (M1) and first premolar (PM1) levels. Data were analyzed using paired t-test and sample t-test.

Results: Midpalatal suture separation was found in $100 \%$ of the patients and the pattern of midpalatal suture opening was parallel in both groups. The total expansion at M1 level was 5.9 $\mathrm{mm}$ in the hybrid, and $4.7 \mathrm{~mm}$ in the absolute BBME group. The skeletal contributions were $56 \%$ and $83 \%$ of the TE in hybrid and absolute BBME groups at the M1 level, respectively. Subjects in the absolute BBME group experienced significantly less dental buccal tipping $\left(0.5^{\circ}\right.$ for $\mathrm{M} 1$, and $-1 \circ$ for PM1), and BBT loss $(0.2 \mathrm{~mm}$ for M1, and $0.4 \mathrm{~mm}$ for PM1) than the hybrid BBME group, $(\mathrm{P}<.05)$.

Conclusion: The use of absolute BBME in adolescent patients increased the skeletal effects, and decreased the dental tipping and buccal bone reduction compared to the use of hybrid BBME. Both types of BBME can be clinically acceptable nonsurgical treatment option for correcting mild to moderate maxillary transverse discrepancies in growing patients. 


\section{DEDICATIONS}

To my wife, Ghaddy. Thank you for standing with me through our amazing journey. You are my motivation to keep on going and the reason of everything good that happens in my life! I know that god loves me because he sent you to complete me, to make my life easier and to help me succeed.

To my son, Bassel. Thank you for adding joy and happiness to our lives. When I tell you I love you, I don't say it out of habit or to make a conversation, I say it to remind you that you are the best thing that ever happened to me.

To my father, dad, thank you for your support. There is no one who can compare to you; your guiding hand on my shoulder will remain with me forever.

To my mother, even through my deepest sadness of losing you, I am still forever grateful that you were the best mother I could have ever asked for!

To my brother, thank you for being my twin, for always dealing with my mess ups, and for taking care of me. I am the happiest person ever because I have such an amazing brother.

To my sisters, thank you for always being there for me; thank you Bayan, Batoul, and Ola. No words can describe how much you mean to me.

To my family and friends, thank you for all your support. 


\section{ACKNOWLEDGEMENTS}

I would like to take the opportunity to thank the following individuals who have played pivotal roles in my specialty training:

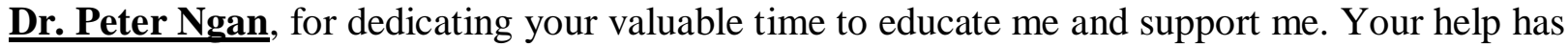
been invaluable to me, and I don't know how I would have managed without your help and support.

Dr. Chris Martin, for your endless encouragement, support and guidance. I will always be thankful for everything you taught me.

Dr. DeBiase, I will never forget how you supported me; and will always remember our amazing meetings. Thank you for everything you have done for me and my family.

Ms. Jun Xiang, for your tireless effort in completing the statistical analyses. You have gone above and beyond, and it is much appreciated.

Dr. Sercan, for helping me collecting the sample and for your encouragement throughout the process.

Professor Hong He Wuhan, for sharing the sample with me and answering our questions throughout the process. 


\section{Table of Contents}

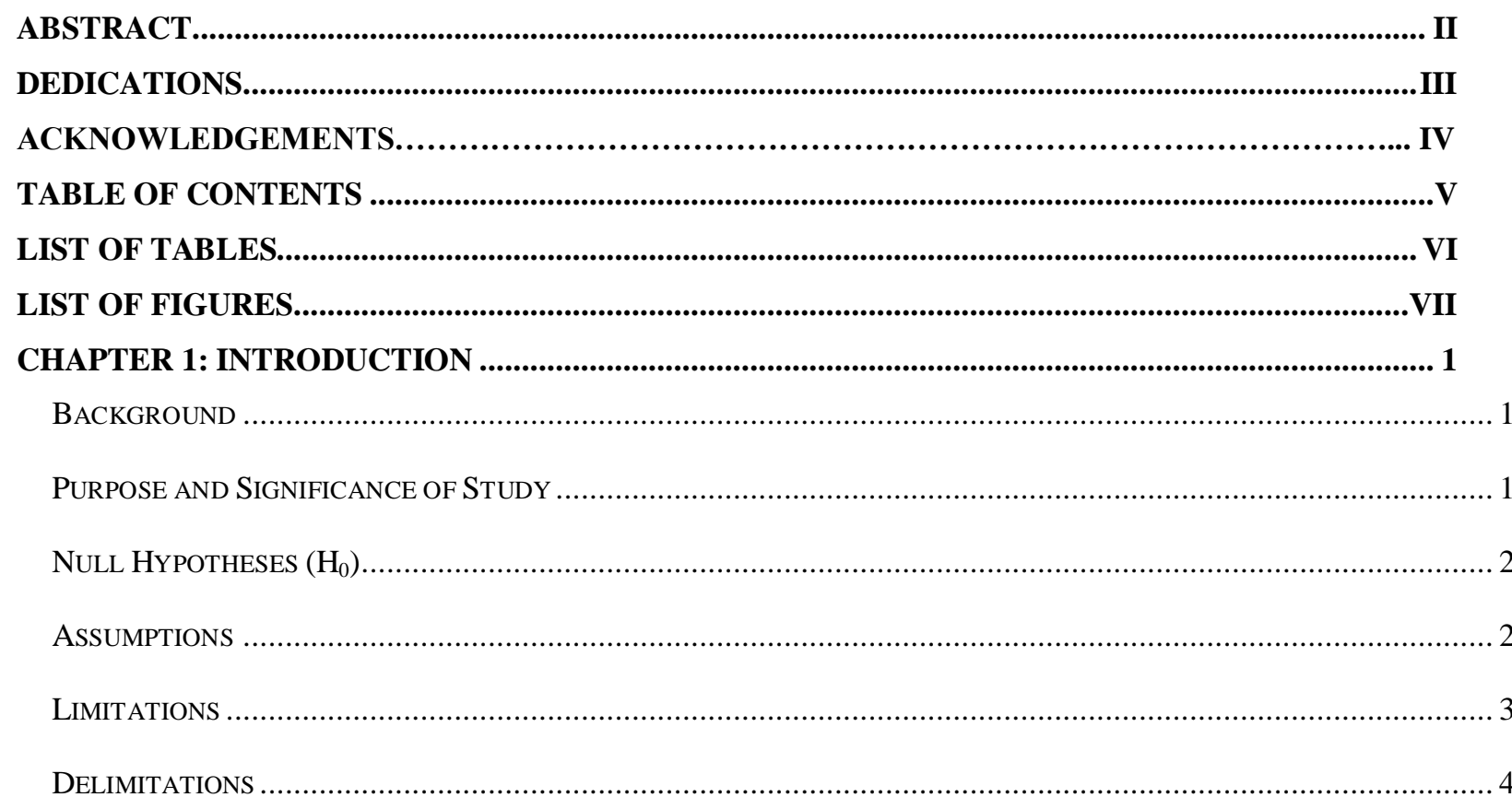

CHAPTER 2: REVIEW OF THE LITERATURE.............................................................................. 5

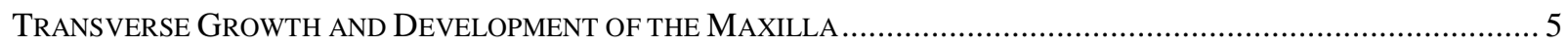

Maxillary Transverse Deficiency: Description, Prevalence, and Etiology ...............................6

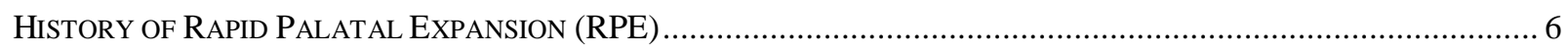

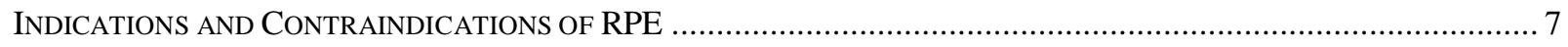

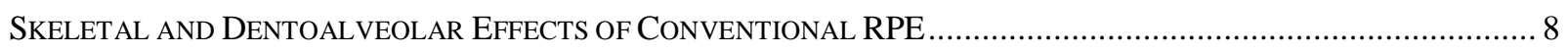

SURGICALLY ASSISTED RAPID PALATAL EXPANSION (SARPE) ….......................................................... 8

MICRO-IMPLANT ASSISTED MAXILLARY EXPANSION (MARPE) ............................................................... 9

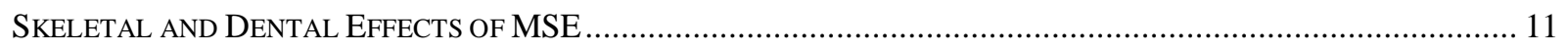

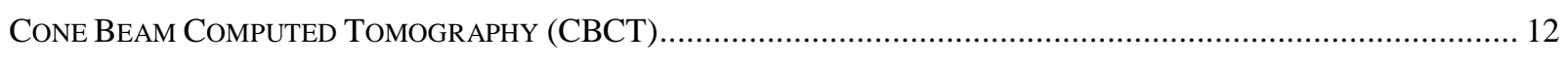

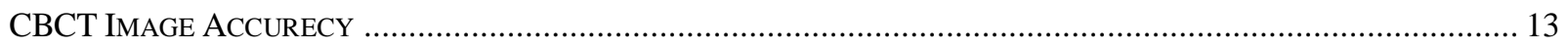

CHAPTER 3: EXPIREMNTAL MATERIAL AND METHODS.........................................15

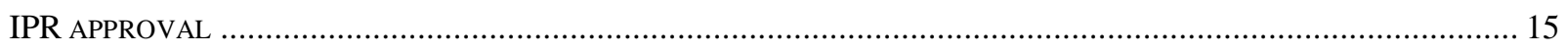

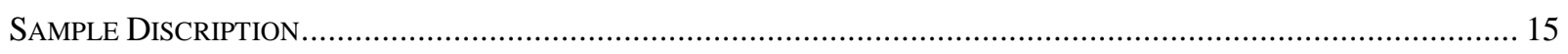

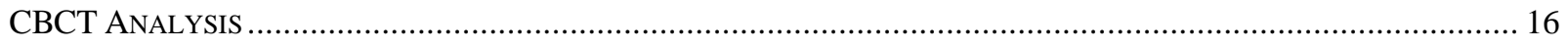




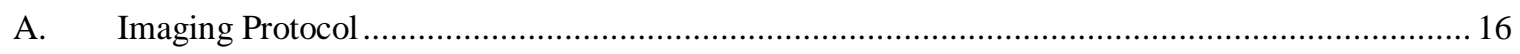

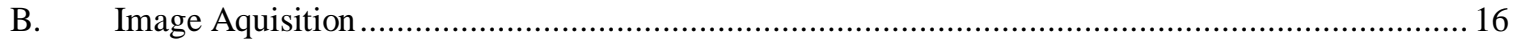

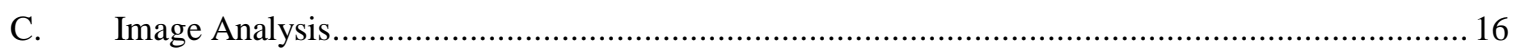

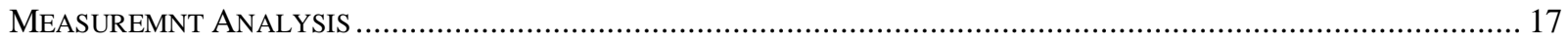

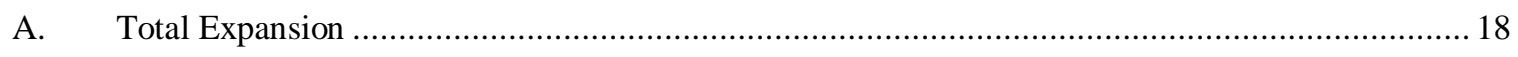

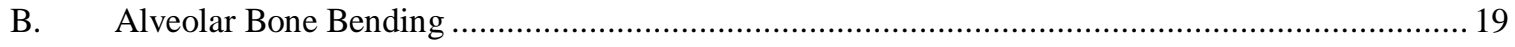

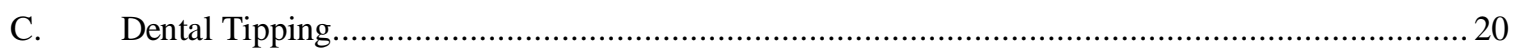

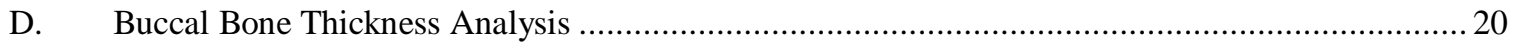

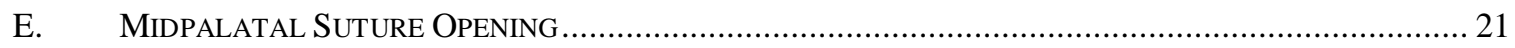

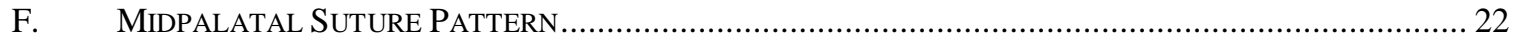

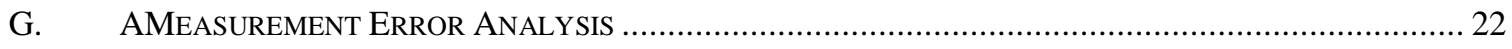

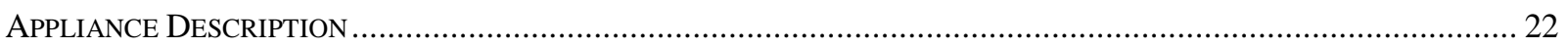

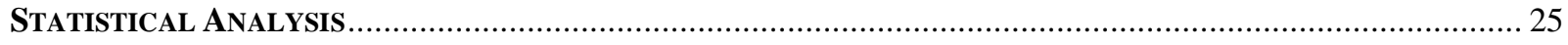

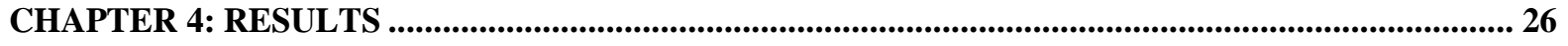

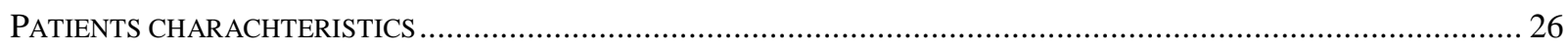

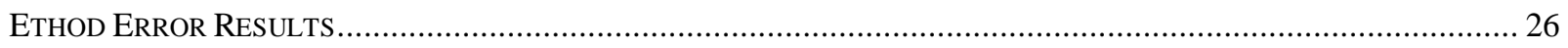

Skeletal, Dentoalveolar and Periodontal Changes in HYbrid BBME Patients ................................. 28

Skeletal, Dentoalveolar and Periodontal Changes in Absolute BBME Patients ............................. 31

COMPARISON BETWEEN HYBRID AND ABSOLUTE BBME APPLIANCES .........................................

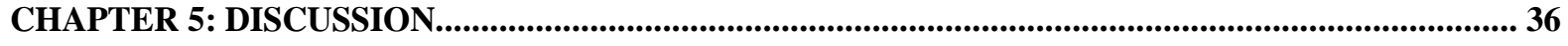

CHAPTER 6: SUMMARY AND CONCLUSIONS.................................................................................... 40

CHAPTER 7: RECOMMENDATIONS FOR FUTURE RESEARCH................................................... 42

REFERENCES.................................................................... 43

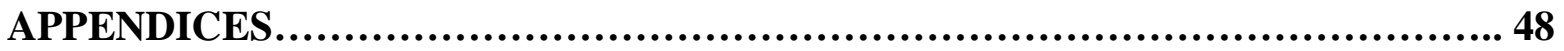

APPENDIX A: IRB APPROVAL..........................................48

APPENDIX B: PERMISION LETTER FROM WUHAN UNIVERSITY …..................................... 50

APPENDIX C: PERMISION LETTER FROM TUFTS UNIVERSITY ............................................. 51 


\section{List of Tables}

Table 1. Reliability coefficients for measurements.........................................26

Table 2. Comparison of pre and post expansion measurements using MSE .29

Table 3. Comparison of pre and post expansion measurements using absolute BAME ................. 32

Table 4. Comparison of difference (T2-T1) measurements between MSE and BAME...........................35 


\section{LIST OF FIGURES}

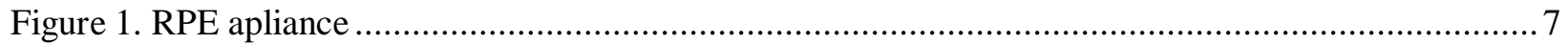

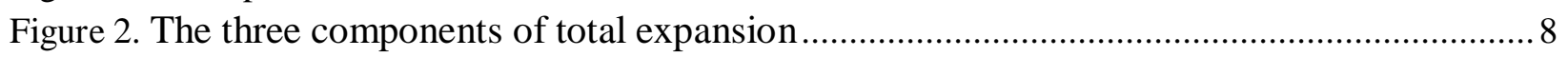

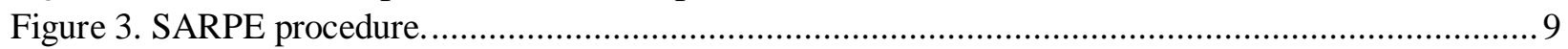

Figure 4. MSE

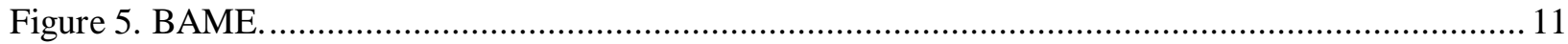

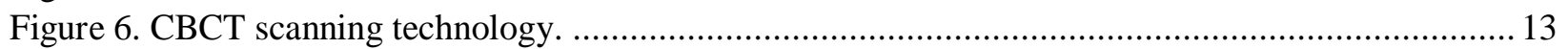

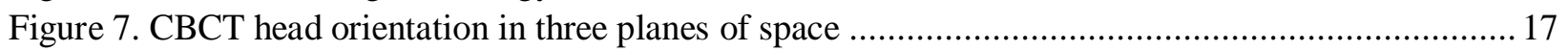

Figure 8. Measurement of intermolar width (IMW) on a coronal cross-sectional slice. ......................... 18

Figure 9. Measurement of interpremolar width (IPMW) on a coronal cross-sectional slice. ................... 19

Figure 10. Measurement of alveolar bone bending (ABB) angle for M1 on a coronal cross-sectional slice

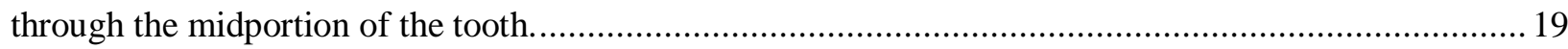

Figure 11. Measurement of dental tipping (DT) angle for M1 on a coronal cross-sectional slice through

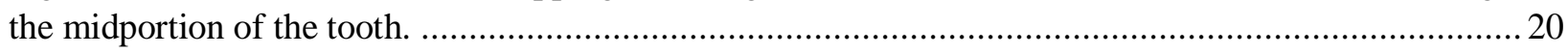

Figure 12. Measurement of buccal bone thickness (BBT) for PM1 and mesiobuccal root of M1 on an axial

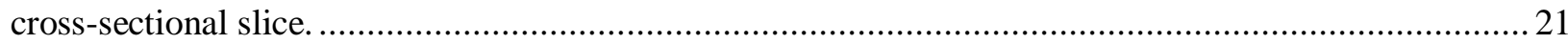

Figure 13. Measurement of sutural expansion on an axial cross-sectional slice through the midpalate at C,

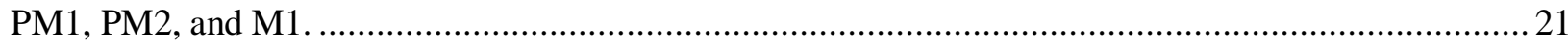

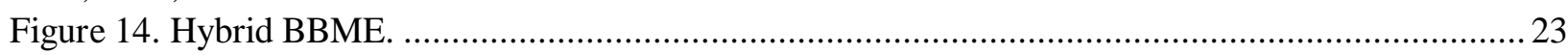

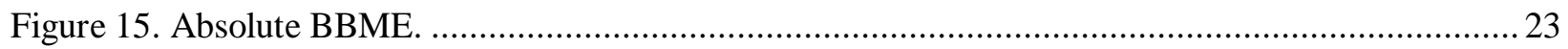

Figure 16. Bi-cortical engagement ian palatal and nasal floor......................................................... 24 


\section{CHAPTER 1: INTRODUCTION}

\section{Background}

Maxillary transverse deficiency is a common orthodontic finding that is reported in $21 \%$ of children and $10 \%$ of the adult population. ${ }^{1}$ Orthopedic maxillary expansion is used to correct skeletal maxillary transverse deficiency, posterior dental crossbites, or increase the arch perimeter. ${ }^{2,3}$ The primary goal of maxillary expansion is to maximize the orthopedic effect, while minimizing the movement of teeth. In tooth-borne expanders, the expansion forces are transmitted through the teeth and into the skeletal structures; which may decrease the amount of force transferred to the skeletal structures and result in undesirable tooth movement. ${ }^{4}$ This led to the introduction of the first bone-borne appliance (distractor) in 1999. Bone-anchored palatal expanders transmitted the expansion forces directly to the skeletal components, resulting in more

skeletal movement. ${ }^{5,6,7,8,9,10}$ Subsequently, there are variety of bone-borne expander designs available in the market. One form of bone-borne maxillary expander (MARPE) is the MSE which uses mini-implants (bone-borne) and posterior teeth (tooth-borne) for orthodontic anchorage. The other form of MARPE is the BAME, which uses only mini-implants as bone-borne anchorage. It is not clear in the literature if there is a difference in skeletal and dental changes with these two types of expanders. ${ }^{11}$

\section{Purpose and Significance of Study}

The purpose of this study is to compare the skeletal, dentoalveolar, and periodontal changes between the MSE and the BAME using cone-beam computed tomography (CBCT). 


\section{Null Hypotheses $\left(\mathrm{H}_{0}\right)$}

- $\mathbf{H}_{\mathbf{1}}$ There is no midpalatal suture opening in patients treated with expander appliance among the two types of expanders

- $\mathbf{H}_{2}$ There is no significant difference in midpalatal suture opening in the axial plane at the canine (C), first premolar (PM1), second premolar (PM2), and first molar (M1) between the two types of expanders at palatal floor

- $\mathbf{H}_{3}$ There is no significant differences in midpalatal suture expansion pattern in the axial plane between the two types of expanders

- $\mathbf{H}_{4}$ There is no significant difference in the amount of total expansion (TE) between T1 and T2 measured at PM1 and M1 between the two types of expanders

- H5 There is no significant difference in the alveolar bone bending (ABB) angle between T1 and T2 measured at PM1 and M1 between the two types of expanders

- $\mathbf{H}_{6}$ There is no significant difference in the dental tipping (DT) angle between T1 and T2 measured at PM1 and M1 between the two types of expanders

- $\mathbf{H}_{7}$ There is no significant difference in the buccal bone thickness (BBT) between T1 and T2 measured at PM1 and mesiobuccal root of the M1 between the two types of expanders.

\section{Assumptions}

1. The CBCT scan resolution was adequate to detect skeletal, dental and periodontal landmarks, without patient movement contributing to the introduction of radiographic artifacts

2. The CBCT scans were $1: 1$ without the need for calibration 
3. The operator in this study had working knowledge of the technology utilized in the analysis

4. Pre-treatment CBCT scans were taken prior to any orthodontic or orthopedic intervention and post-expansion scans were taken immediately at the end of the appliance activation

5. CBCT with Dolphin three-dimensional (3D) Imaging software allows for accurate landmark identification and quantification of linear and angular measurements.

\section{Limitations}

1. Limited sample size of subjects in the database from the Departments of Orthodontics at Tufts University School of Dentistry and Wuhan School of Stomatology

2. Lack of long-term follow up of the treatment effects

3. There is patient-related variability e.g. medical history, age, gender, ethnicity, skeletal maturity, craniofacial anatomy, and bone anatomy and physiology among the subjects

4. There is treatment-related variability e.g.

a. The amount of appliance activation_needed to resolve transverse jaw disharmony

b. Anteroposterior positioning of the appliance along the palate

c. The number of teeth selected for appliance anchorage

d. The number of bi-cortically engaged microimplants

5. CBCT scans were taken from two different 3D units, may have different setting 
6. CBCT scans may have artifacts from subject movements, amalgam fillings, metal crowns, mini screws, expanders, and machine specifications

7. Investigator's ability to manipulate $3 \mathrm{D}$ imaging software to accurately orient $\mathrm{T} 1$ and $\mathrm{T} 2$ CBCT scans, determine landmarks, and obtain linear and angular measurements for reliable comparison

8. Resolution of CBCT in Dolphin imaging software and noises and scatter produced by expander and micro-implants made it difficult to precisely identify particular landmarks in some patients (i.e. buccal cortical plate and palatal shelf, midpalatal suture).

\section{Delimitations}

1. Subjects selected based on treatment with particular type of MARPE appliance

2. Subjects selected if there is no history of previous orthodontic or orthopedic treatment

3. No presence of Craniofacial syndrome or deformities due to abnormal development or trauma. 


\section{CHAPTER 2: REVIEW OF THE LITERATURE}

\section{Transverse Growth and Development of the Maxilla}

The palate develops from the $6^{\text {th }}$ to the $12^{\text {th }}$ week of embryonic life. The primary palate is the secondary ossification center of the maxilla, arising from the medial nasal processes in the intermaxillary segment. During the $8^{\text {th }}$ week of intrauterine development, ossification centers

merge to form the maxilla. ${ }^{12}$ The primary palate establishes a palatine view of the suture between the premaxilla and the maxilla with the secondary palate, without leaving any signs or marks in the adult individual. The same process does not apply to the palatal bone with which the suture is well established. ${ }^{13}$

The osteogenic process in the midpalatal suture is similar to the growth and bone remodeling provided by the periosteum in other bone surfaces, and fulfills the requirements of adjacent tissues by means of external stimuli also known as functional demands. ${ }^{14}$ The midpalatal suture is not a center of maxillary bone growth, but it responds to osteogenic stimuli. ${ }^{15,16}$

The midpalatal suture has bone margins with thick connective tissue interposed between them, and it does not represent the fusion of maxillary palatal processes only, but also the fusion of palatal processes of the jaws and horizontal osseous laminae of palatal bones It has got three segments: the anterior segment (before the incisive foramen, or intermaxillary segment), the middle segment (from the incisive foramen to the suture transversal to the palatal bone ) and the posterior segment after the suturetransversal to the palatal bone. ${ }^{13}$

Both the macroscopic and microscopic morphologies of the midpalatal suture were described by Ennes ${ }^{13}$ and, Ennes et al, ${ }^{17}$ including its morphological changes in terms of the chronological evolution of humans, primates, rabbits and rats. 


\section{Maxillary Transverse Deficiency: Description, Prevalence, and Etiology}

Maxillary transverse deficiency is a common orthodontic finding that is reported in $21 \%$ of children and $10 \%$ of the adult population. ${ }^{1}$ Previous research has indicated that approximately $18 \%$ of mixed-dentition patients have a transverse maxillary constriction. Traditionally, they are treated with rapid palatal expansion techniques that rely on a combination of orthopedic and dental expansion to correct the skeletal disharmony. ${ }^{18}$

Multiple etiological factors have been described for maxillary transverse deficiency. Causes of the condition may include developmental disturbances, such as clefts in the lip and palate, mouth breathing, parafunctional habits like thumb sucking, atypical phonation and swallowing. ${ }^{19}$

\section{History of Rapid Palatal Expansion (RPE)}

The use of maxillary expansion appliance (Figure 1) could date back to 1860s, when Angell came up with the concept "maxillary expansion", which opened the mid-palatal suture laterally by a palatal expansion appliance. ${ }^{20}$ European orthodontists, Maxillary Orthopedics enthusiasts, brought the technique back based on the works by Derischsweiler (1953) and Korkhaus (1960). ${ }^{21}$ American Orthodontics became interested in when Haas (1961), carried out the procedure in pigs and proved the existence of the microscopic events implicated. The technique employed in patients with atrophic maxilla achieve positive outcomes and the procedure was considered safe and as an alternative for more complicated cases, such as Class II malocclusion associated with posterior crossbite. $^{13}$

Many types of RPE appliances have been developed with different rates of expansion, but the principles are essentially the same. By exerting a rapid transverse force on the maxillary dentition, 
the midpalatal suture is disrupted and separated, leading to increased cellular activity in that area that induces bone remodeling along the sutural areas. ${ }^{18,22}$ If the patient performs between 2 and 4 turns every day, expansion will occur within one to two weeks. The desired extension is achieved, including overcorrection and relapse. The latter often occurs as a result of lack of balance or tensegrity among the pieces that form the midface. ${ }^{13,14}$

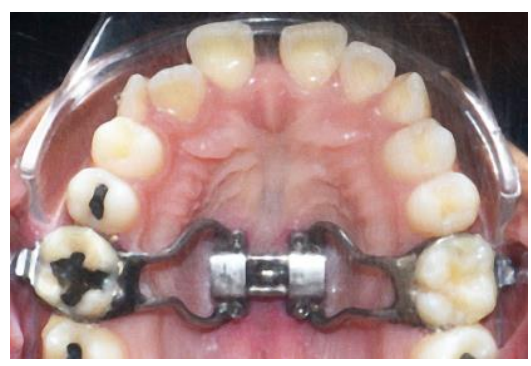

Figure 1. RPE applaince. ${ }^{13}$

\section{Indications and Contraindications of RPE}

The aim of maxillary expansion was to optimize the dentofacial orthopedics effect while minimizing the dentoalveolar side effects, thus the total expansion obtained through the usage of RPE, can be categorized into skeletal expansion, alveolar expansion, and bending or tipping of the teeth (Figure 2). ${ }^{3,4}$ Patients who have moderate upper arch crowding or unilateral or bilateral posterior crossbites as a result of maxillary constriction may particularly benefit from RPE treatment. Individuals with anteroposterior discrepancies with a narrow upper jaw such as skeletal Class II, Division 1 or Class III malocclusion with borderline skeletal and pseudo Class III problems are also suitable candidates for treatment with an expander device. Cleft lip and palate patients with collapsed maxillae are also RPE candidates. ${ }^{19}$ 


\section{Skeletal and Dentoalveolar Effects of Conventional RPE}

Although opening of the midpalatal suture is the main goal of RPE, the expansion force acting on the palatal aspect of the tooth crowns causes undesired dental effects, such as buccal tipping, decrease in buccal bone thickness and marginal bone levels, ${ }^{23-28}$ and volume loss and thinning of the anchor teeth. ${ }^{29,30}$ Changes related to the buccal bone thickness and root morphology are mostly reversible. ${ }^{30,31}$ The reduction of cortical bone was even more pronounced on the teeth that served as direct anchorage to the expander, which was attributed to the tipping movement of the teeth. Moreover, this comes with several disadvantages, such as age limitation, dentoalveolar tipping, root resorption, and bone dehiscence, and the lack of long-term stability. ${ }^{3,23,32}$ It was reported that skeletal expansion only accounts for about $38 \%$ of total expansion, ${ }^{33}$ and the recurrence rate was $35 \%$ to $50 \% .{ }^{34}$ However, these side effects may be prevented from occurring in the first place by using miniscrews as anchorage units in bone-borne RPE applications. ${ }^{35}$

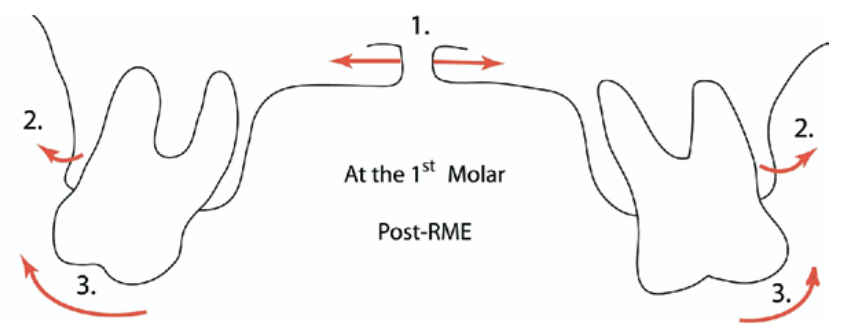

Figure 2. The three components of total expansion 1. Skeletal expansion; 2. Alveolar bending, 3. Dental tipping. ${ }^{34}$

\section{Surgically Assisted Rapid Palatal Expansion (SARPE)}

Brown introduced the concept of surgically assisted rapid palatal expansion (SARPE) in $1938^{36}$. SARPE procedure (Figure 3) gradually became the main treatment modality for adult patients with maxillary transverse discrepancy. ${ }^{37,38}$ In adults, additional surgical weakening of certain anatomic structures of the midface is required to allow maxillary expansion and opening 
up of the midpalatal suture. ${ }^{39}$ With skeletal maturity, there is increased ossification in the circummaxillary sutures, increased thickness of the bony structures, reduction in the elasticity, and increased interdigitation of the median palatal suture. All these factors provide resistance to opening of the midpalatal suture and stable widening of the maxilla. ${ }^{40,41}$

Advantages of treatment with SARPE were predictable skeletal and dental changes, and a low rate of relapse (5\% to $25 \%) .^{38,42}$ resulting in stable maxillary expansion in adults. ${ }^{40}$ However, many adult patients were discouraged from choosing this treatment due to its the invasive nature, risks, complications and cost of the surgical procedure. ${ }^{43}$

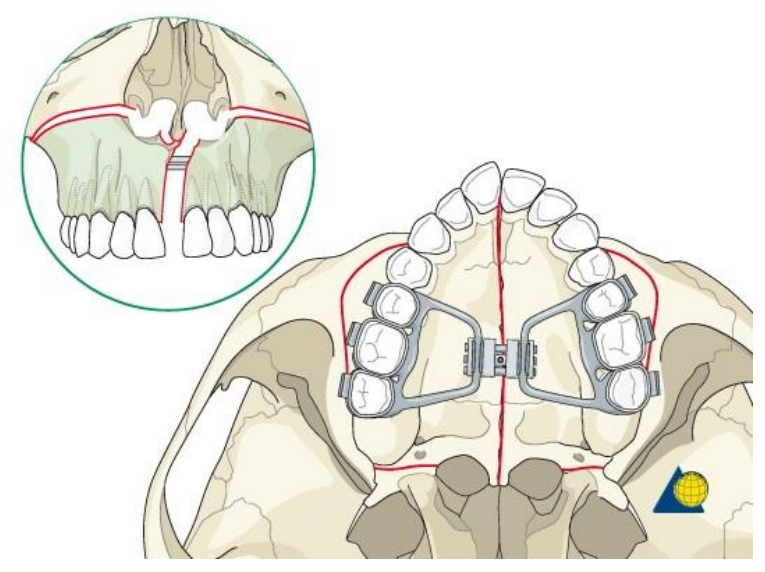

Figure 3. SARPE procedure. ${ }^{44}$

\section{Micro-implant Assisted Maxillary Expansion (MARPE)}

With the innovation of miniscrews, it is now possible to reinforce the anchorage system of RPE without the support of tooth structure because miniscrews serve as the orthodontic absolute anchorage. Bone anchored RPE was reported to transmit a direct expansion force to the palatal bone, which contribute in a more skeletal opening of the suture, instead of bending of the maxillary alveolar bone as the force vector located near the bone., ${ }^{4,45}$

With increasing skeletal maturity, heavy interdigitation of the suture makes the separation of the two halves of the maxilla unfeasible using conventional tooth-borne RPE appliances. 
Therefore, MARPE appliances were originally developed for patients in whom conventional RPE was contraindicated. ${ }^{46}$

Wehrbein et, al, (1996) firstly introduce the use of miniscrews in the palatal area because the palate is covered with keratinized gingival and gave good flexibility ${ }^{47}$ Wilmes et al. introduced the tooth-bone-anchored maxillary skeletal expander to any device that is used for expanding maxilla that is skeletally and dentally anchored. ${ }^{48}$ These devices are reported to produce greater skeletal expansion ensuring minimal alveolar/dental tipping and at the same time offer greater stability. Maximization of the skeletal expansion through skeletal anchorage enhancement is by recruiting both palatal and nasal cortices. At the same time, a support wire connecting the expander to the teeth enhances the stability. This is a recent concept and such expanders are referred to as maxillary skeletal expander (MSE) (Figure 4). ${ }^{49,50}$ The routine and safe use of orthodontic miniimplants in the anterior palate has encouraged the use of the so-called hybrid expanders, which are partially bone-borne and partially tooth-borne. ${ }^{39}$

The other type of MARPE is the bone-anchored maxillary expanders (BAME) (Figure 5). This bone-borne maxillary expander enables purely skeletal expansion without any dental side effects. Due to its rigid construction and its reliable anchorage maxillary expansion without surgical assistance, it appears to be effective in more adult patients. ${ }^{51}$ BAME do not demonstrate any translational dental movements or buccal tipping because no teeth are involved. After the expansion, they exhibit minor spontaneous palatal tipping of the buccal teeth, as Carlson et al described for the maxillary canines only. ${ }^{49}$

Although MARPE are capable of producing greater skeletal expansion, there are concerns regarding its stability. The interlocked suture in mature patients undergoes significant torsion in three dimensions. As it splits, the two halves of the maxilla twist away from each other, and the 
implants used to anchor the RPE will experience additional strain and may tip. This will subsequently result in either loosening or breakage of the implant, thereby rendering the expansion device unstable. ${ }^{49}$

The introduction of MARPE appliances provided a new alternative treatment modality for clinicians and adolescent patients with maxillary transverse deficiency. A thre dimensional finite element analysis showed that these devices had greater skeletal and less dental side effects than traditional RPE..$^{52,53}$

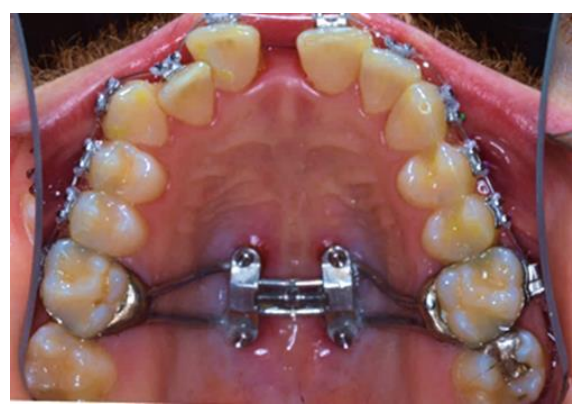

Figure 4. MSE.

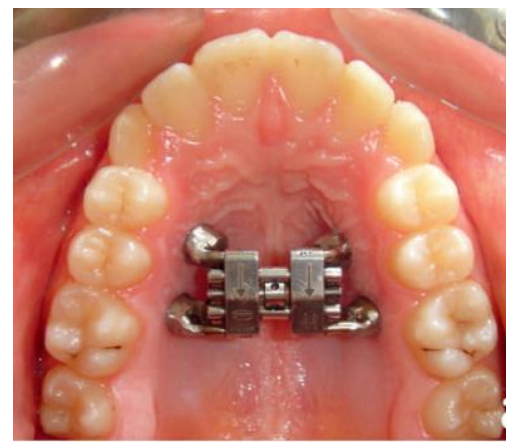

Figure 5. BAME. ${ }^{35}$

\section{Skeletal and Dentoalveolar Effects of MARPE}

In adults, due to the maturation of the midpalatal sutures and resistance from the zygomatic buttress, the response to palatal expansion with RPE is less successful. The resulting widening of the maxillary width is more due to alveolar bone bending and dental tipping in adults. ${ }^{54}$ 
Lagravere et al, reported the effects of RPE with bone anchorage indicating there was less dental tipping than the usage of RPE alone. The usage of miniscrew assisted RPE was effective in preventing the negative side effects that were commonly seen with the usage of RPE alone. Therefore, many clinicians opted to use miniscrews as a noninvasive expansion alternative method. ${ }^{10,55}$ Mosleh et, al, stated that the expansion force on palatal bone will produce a more parallel opening, without causing unwanted tooth movement. ${ }^{56}$ Lin et, al, conducted a study that compares tooth-borne and bone-borne RPE in late adolescence using CBCT, reported both expanders produced expansion, but the maxillary skeletal expander produced greater orthopedic effects and a more parallel opening of the suture. Subjects in the MSE group showed less change of alveolar inclination and tooth axis compared to subjects in RPE group. The change of teeth angulation was a combination of bone bending and tipping of the teeth. As teeth were surrounded by alveolar bone and undergoing remodeling process, it was hard to objectively separate bone bending and tipping of the teeth. The lesser tipping found in MSE can be explained with the use of skeletal anchorage. ${ }^{57}$

A portion of the change in inclination is also likely due to the bodily rotation of the maxillary structure on each side. Buccal rotation or bending of the segments occurs throughout the arch, but the amount is greater from posterior to anterior. This is most likely the reason for dental tipping in expansion patients even without tooth anchorage and may also explain the angulation changes of the molars and premolars. ${ }^{18}$

\section{Cone Beam Computed Tomography}

CBCT scanners (Figure 6) have been available for craniofacial imaging since 2001 in the United Sates. Their compact size and relatively low radiation dosage make the CBCT scan an 
imaging modality that helps address the previously stated challenges effectively and efficiently. ${ }^{58}$ CBCT has made it possible to acquire 3D image volumes of all structures in the maxillofacial complex. With the use of specific software and acquisition protocols based on individual needs, these digital volumetric scans can be turned into multiple planar view images (axial, coronal and sagittal). Software tools also allow bone structure measurements to be obtained as well as 3D assessment of soft tissues, and the shapes, volumes and features of the face. ${ }^{59}$

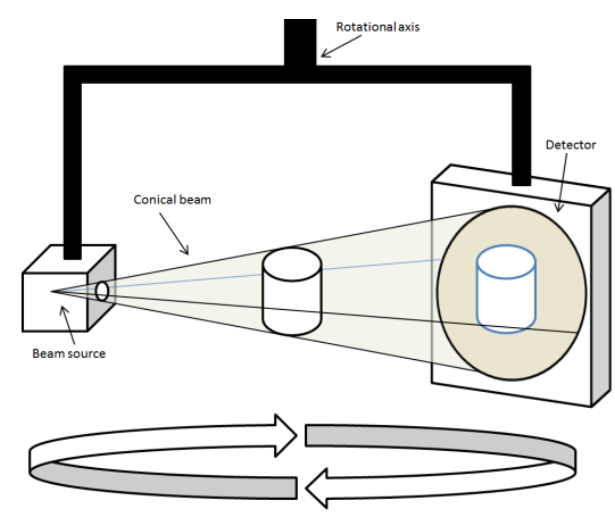

Figure 6. CBCT scanning technology. ${ }^{60}$

\section{CBCT Image Accuracy}

CBCT scans allow the orthodontist to assess the patient's hard and soft tissue in three dimensions. The accuracy and reliability of such images have been tested and were found to be adequate for implant planning, periodontal disease quantification, and assessment of tumor/lesion volumes. Today, existing software permits us to take full advantage of CT scans in performing 3D measurements and developing 3D craniofacial analyses. These 3D measurements, made on CT images, can be more accurate and reproducible and have the potential to aid in the craniofacial diagnosis of facial asymmetries, functional shifts, and canted occlusal planes. CBCT craniometric measurements are accurate to a subvoxel size and potentially can be used as a quantitative 
orthodontic diagnostic tool. ${ }^{61}$ Presence of soft tissue, as well as different voxel size, affect the precision of the data. A customized resolution protocol must be chosen according to the accuracy needed. ${ }^{62}$ When CBCT is employed, the accuracy and reliability of craniofacial measurements is shown to be better, compared to the $2 \mathrm{D}$ cephalogram. ${ }^{63}$ 


\section{CHAPTER 3: EXPERIMENTAL MATERIALS AND METHODS}

\section{IRB Approval}

Protocol \#1909722030 was reviewed and exempted by the Institutional Review board at West Virginia University (See Appendix A). Permission to use patient data was obtained from Wuhan School of Stomatology and Tufts University School of Dentistry (See Appendix B, C).

\section{Sample Description}

A total of 36 patients were examined for this retrospective study. Sixteen patients (10 female, and 6 male), with and average age of 14.9 years, from the archive of the Department of Orthodontics at Wuhan University treated with the MSE were compared to 20 patients (17 female, and 3 male), with average age of 13.8 years, from the archive of Department of Orthodontics at Tufts University treated with the BAME. Two patients were excluded from the study due to an insufficient field of view.

The inclusion criteria were as follows:

1. Young adolescent patients with transverse discrepancy treated with expanders, particularly with the use of one of two types of MARPE appliance

2. CBCT scans of diagnostic quality, including all pertinent anatomy, captured before and immediately after expansion treatment

The exclusion criteria were as follows:

1. Patients with previous history of orthodontic, orthopedic treatment or orthognathic surgery 
2. Patients with craniofacial abnormalities, facial asymmetry or deformities due to abnormal development or trauma

3. Patients with no suture opening after expansion

4. Lack of full field of view (did not include landmarks needed)

\section{CBCT Assessments:}

\section{A. Imaging Protocol}

The DICOM (digital imaging and communications in medicine) files of the subjects participating in this study were de-identified and coded by numbers to protect patient privacy.

The CBCT scans in Wuhan University School of Stomatology were obtained with the NewTom VGi9 3D CBCT unit (Imola, Italy) while in Tufts University School of Dentistry were obtained with the Kodak CS 9000 3D CBCT unit (CareStream Health, Inc, Rochester, NY, USA). The images were calibrated using the same parameters that included exposure of $10 \mathrm{~mA}$ for 32.5 seconds, power of $70 \mathrm{kVp}$, and $76-\mu \mathrm{m}$ voxel size with volume dimensions of $8 \mathrm{~cm} \times 8 \mathrm{~cm}$.

\section{B. Image Acquisition}

CBCT were taken for each patient at $\mathrm{T} 1$, pre-treatment; and at $\mathrm{T} 2$, immediately postexpansion. Patients were instructed to set up keeping the Frankfort plane paralleled to the floor and clenching on intercuspal position during scanning.

\section{Image Analysis}

\section{CBCT Image Volume Reorientation}


For purposes of standardizing the image analysis procedure and setting an identical reference plane for the $\mathrm{T} 1$ and $\mathrm{T} 2$ stages, all CBCT volumes were adjusted in three planes of space (sagittal, axial, and coronal) (Figure 7). The image volume reorientation performed within the Dolphin imaging software (version 11.95, Dolphin Imaging \& Management Solutions, Chatsworth, Calif.) (Figure 7). The image volume reorientation was process and CBCT analysis were adopted from the method by Ngan et al, ${ }^{64}$

A. The sagittal view was reoriented parallel to the software's horizontal indicator line that transverse the middle of the palatal plane (ANS-PNS)

B. The axial view was oriented parallel to the software's horizontal line that connected the left and right lingual cusps of the upper first premolars

C. The coronal view was oriented parallel to software's horizontal position indicator line that connected the left and right intersection of lateral contour of the maxillary alveolar process and the lower contour of the maxillozygomatic process of the maxilla.
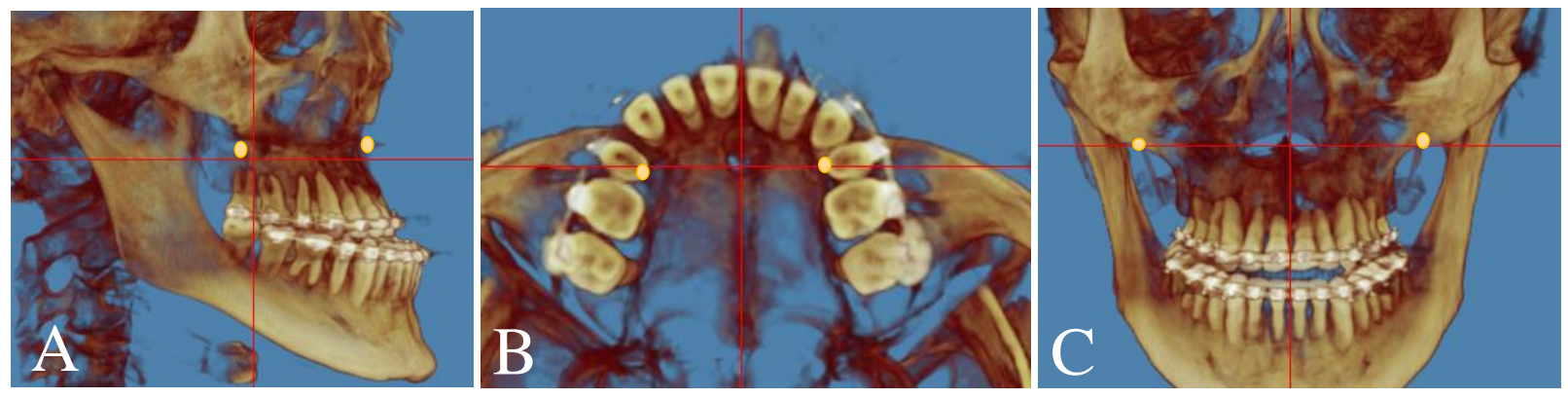

Figure 7. CBCT head orientation in three planes of space; A. Sagittal, B. Axial, and C. Coronal.

\section{Measurements Analysis}

The DICOM images were assessed by Dolphin imaging software; using the dolphin distance measuring tool. 


\section{Total Expansion (TE)}

Total expansion achieved with MARPE appliances includes the direct separation of the maxillary halves at the midpalatal suture (skeletal expansion) along with alveolar bone bending and dental tipping (dentoalveolar expansion). The following equation shows the components of total expansion:

[Total Expansion] $=$ [Midpalatal Sutural Separation $]+$ [Alveolar Bone Bending $]+[$ Dental Tipping]
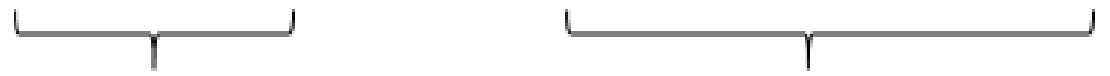

\section{Skeletal (Orthopedic) Expansion Dentoalveolar (Orthodontic) Expansion}

- TE at the first molars (M1) level was defined as the change between (T2-T1) in the intermolar width (IMW), the distance between the palatal cusp tip of the right and left first molars measured in a coronal cross-sectional slice through the center of M1 (Figure 8).

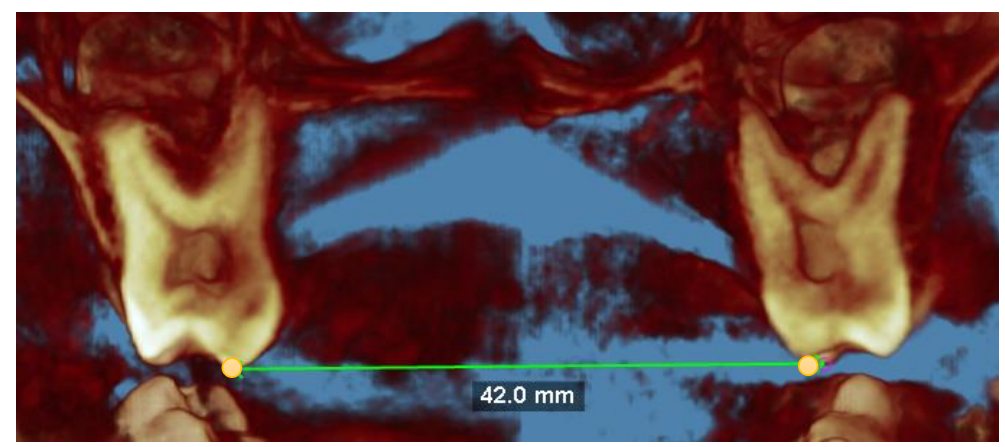

Figure 8. Measurement of intermolar width (IMW) on a coronal cross-sectional slice.

- $\quad \mathrm{TE}$ at the first premolars (PM1) level was defined as the change between (T2-T1) in the interpremolar width (IPMW), the distance between the palatal cusp tip of the right and left first premolars measured in a coronal cross-sectional slice through the center of PM1 (Figure 9). 


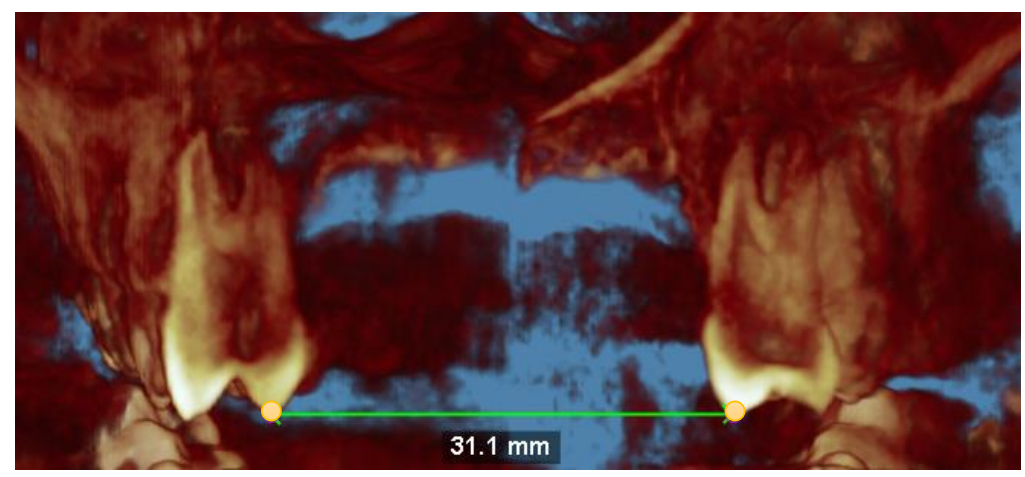

Figure 9. Measurement of interpremolar width (IPMW) on a coronal cross-sectional slice.

\section{Alveolar Bone Bending (ABB) Angle}

ABB was defined as the degree difference (T2-T1) between the palatal alveolar bone angles measured for the anchored teeth PM1, M1 or both, on a coronal cross sectional slice through the midportion of the teeth. Figure 10 shows the ABB angle value obtained for M1 by measuring the intersecting angle formed by a best fit line through the palatal cortical plate and the software's horizontal indicator line that transverse the middle of the palate. A positive change in $\mathrm{ABB}$ indicates alveolar bone bending toward the buccal direction, while a negative change in $\mathrm{ABB}$ indicates alveolar bone bending in the palatal direction.

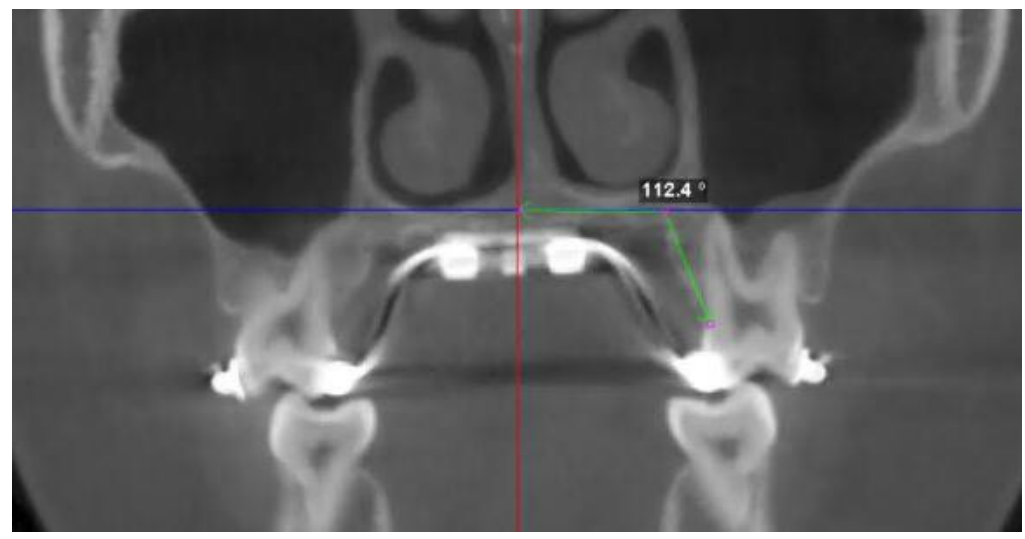

Figure 10. Measurement of alveolar bone bending (ABB) angle for M1 on a coronal crosssectional slice through the midportion of the tooth. 


\section{Dental Tipping (DT) Angel}

Dental tipping was defined as the degree difference (T2-T1) between the dental tipping angle measured for the anchored teeth, PM1, M1 or both, on a coronal cross-sectional slice through the midportion of the teeth. Figure 11 shows the DT angle value obtained for M1 by measuring the intersecting angle formed by a best fit line through the long axis of the tooth and the software's horizontal indicator line that transverse the middle of the palate.

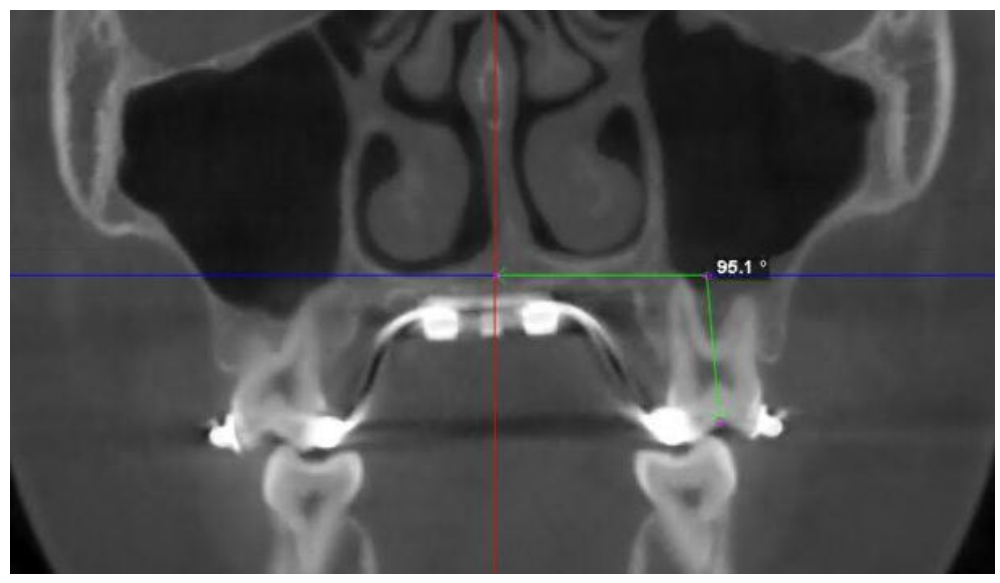

Figure 11. Measurement of dental tipping (DT) angle for M1 on a coronal cross-sectional slice through the midportion of the tooth.

\section{Buccal Bone Thickness (BBT)}

Buccal bone thickness was measured for PM1, and the mesiobuccal root of M1 when PM1, M1 or both was used for appliance anchorage on an axial cross-sectional slice through the furcation of M1 (Figure 12). BBT was defined as the perpendicular distance between the most facial surface of the tested tooth and the external aspect of the maxillary buccal cortical plate. 


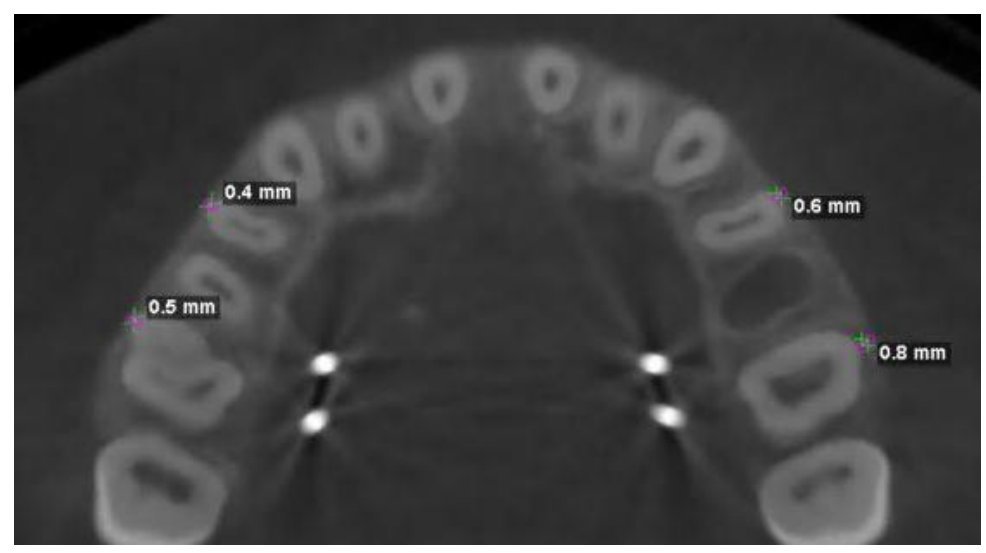

Figure 12. Measurement of buccal bone thickness (BTT) for PM1 and mesiobuccal root of M1 on an axial cross-sectional slice.

\section{Midpalatal Suture Opening}

Measurements were made at the canine (C), first premolar (PM1), second premolar (PM2), and first molar (M1) levels. Suture width opening was measured between the right and left external edges of the suture on an axial cross-sectional slice through the center of the palate (Figure 13).

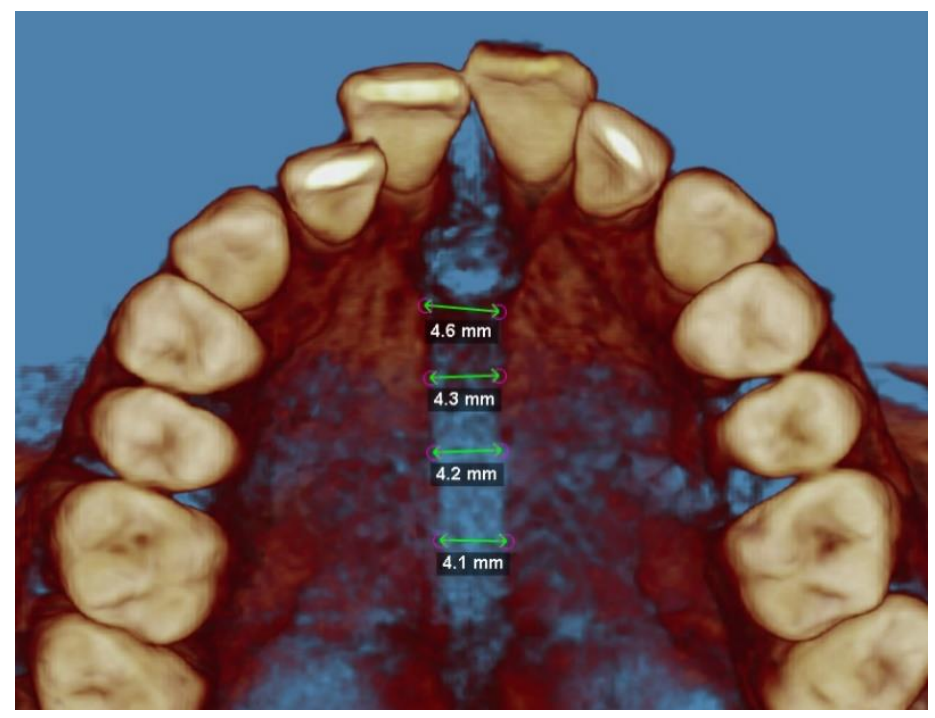

Figure 13. Measurement of sutural expansion on an axial cross-sectional slice through the midpalate at C, PM1, PM2, and M1 levels. 


\section{Midpalatal Suture Expansion Pattern}

Successful midpalatal suture separation was defined as complete opening of the suture anteroposteriorly. Measurements were made at C, PM1, PM2, and M1 levels. Suture width opening was measured between the right and left external edges of the suture on an axial cross-sectional slice through the center of the palate (Figure 13).

\section{Measurement Error Analysis}

The reliability of the measurements is tested by investigating the error in locating and measuring the changes of all landmarks. Ten (29.4\%) randomly selected subjects are analyzed a second time by the same examiner two weeks after the initial measurements. For all variables, differences between the measurements recorded at the first analysis and measurements recorded at the second analysis were compared for each of the 10 individuals. Intra-class correlation coefficients were calculated to evaluate the reliability of the repeated measurements. All statistical tests were two-sided and p-value <.05 was considered statistically significant.

\section{Appliance Description}

The patients included in this study were treated with one of the two types of MARPE.

\section{MSE}

The first appliance consists of a central expansion jackscrew and four attached arms soldered to orthodontic bands, pre-fitted around anchored teeth to facilitate the placement

of the appliance along the palate. Welded to the central expansion screw are four tubes that 
serve as guides for the placement of the microimplants (Figure 14). The patients treated with this appliance were obtained from Wuhan University School of Stomatology.

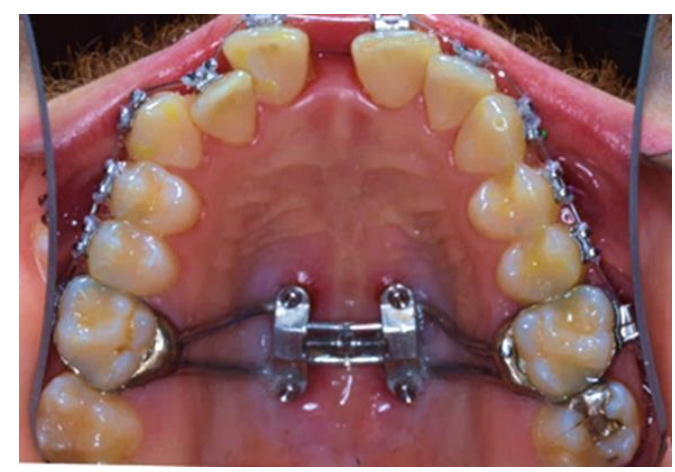

Figure 14. Example of MSE appliance.

\section{BAME}

The second appliance consists of a central expansion jackscrew. Welded to the central expansion screw are four tubes that serve as guides for the placement of the microimplants (Figure 15). The patients treated with this appliance were obtained from Tufts University School of Dentistry.

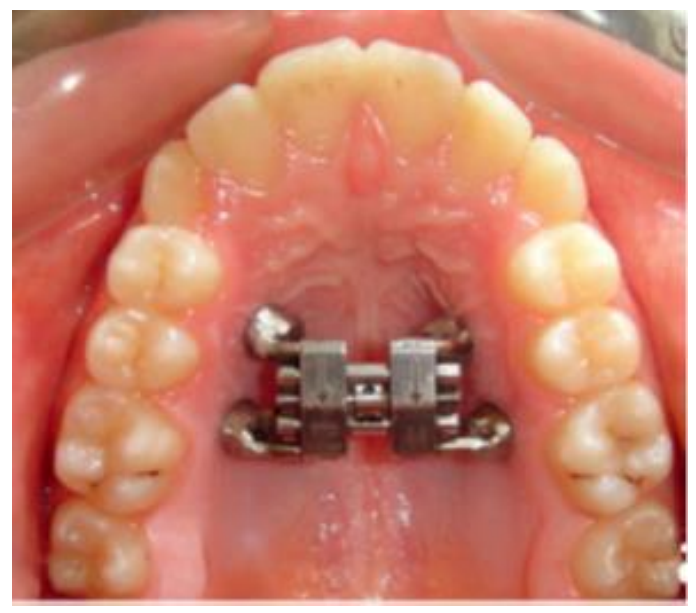

Figure 15. Example of BAME appliance. 
The microimplants allow for fixation of the expander flushed to the palate and are 1.5-1.8 $\mathrm{mm}$ in diameter and $11 \mathrm{~mm}$ in length. The microimplant length allows for bi-cortical engagement of the palatal and nasal floor (Figure 16), while the diameter allows for a secure fit within the tubes, reducing the magnitude of lateral force transfer to anchored teeth during appliance activation.

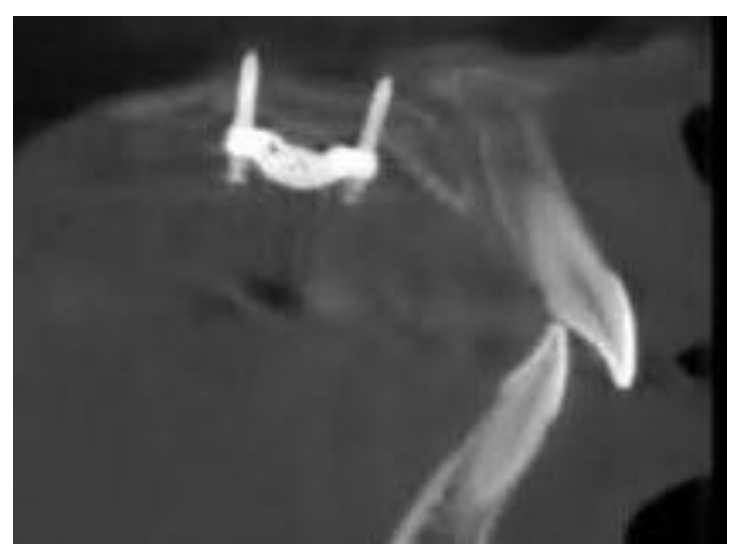

Figure 16. Bi-cortical engagement of the palatal and nasal floor.

Although the same expander appliance was used for all patients in each study sample, there were variations relating to the following:

1. Number of teeth selected for appliance anchorage in Wuhan University School of Stomatology sample. The expander was either banded to four teeth (first premolars and first molars) or two teeth (first molars only).

2. Appliance position. The expander appliance was placed in one of three locations along the palate:

a. On the inclines of the anterior palate distal to the second or third rugae (anterior position) 
b. On the flat surface of the palate around the level of the permanent second premolar (middle position)

c. On the flat surface of the palate $1 \mathrm{~mm}$ anterior to the soft palate around the level of the permanent first molar (posterior position)

3. Appliance activation. The amount of appliance activation each patient received varied with the magnitude of transverse discrepancy between the maxilla and mandible.

- MSE group

\begin{tabular}{|l|c|c|}
\hline \multicolumn{1}{|c|}{ Age of patients } & $\begin{array}{c}\text { Initial expansion } \\
\text { rate }\end{array}$ & $\begin{array}{c}\text { Expansion rate after } \\
\text { opening the diastema }\end{array}$ \\
\hline Early teens $(<\mathbf{1 3})$ & 2 turns/week & 2 turns/week \\
\hline Late teens (13-15) & $2-3$ turns/week & 2 turns/week \\
\hline
\end{tabular}

- BAME group

Two turns a day. The average activation time was $19.7 \pm 3.8$ days.

\section{Statistical Analysis}

All statistical analyses were conducted using SAS (version 9.4, 2013, SAS institute Inc., Cary, NC). Paired t-test was utilized to evaluate skeletal, dentoalveolar and periodontal changes after maxillary expansion using both types of MARPE appliances. To compare the difference between the MSE and the BAME groups in skeletal, dentoalveolar and periodontal changes, two independent sample t-test were conducted. Intra-class correlation coefficients were calculated to evaluate the reliability of the measurements. All statistical tests were two-sided and p-value $<.05$ was considered statistically significant. 


\section{CHPTER 4: RESULTS}

\section{Patients Characteristics}

A total of 36 patients who were diagnosed with maxillary transverse deficiency and treated with one of two types of MARPE werevincluded in the study. Sixteen of these patients treated with MSE, and the other 20 patients were treated with BAME. The age range of the two samples was between 12 and 15 years. Two patients from the second group were excluded from the study due to an insufficient field of view.

\section{Method Error Result}

The reliability coefficient was found to determine the repeatability of the measures made for the variables in this study. Intra-class correlation coefficients of all measurements except two (>0.80) were higher than 0.90, indicating a high level of agreements between the two measurements, and evidence to support the repeatability of measurements (Table 1).

Table 1: Reliability coefficients for measurements

\begin{tabular}{|l|c|}
\hline Variables & Intra-class correlation coefficient \\
\hline IMW pre & 0.994 \\
\hline IMW post & 0.994 \\
\hline IPMW pre & 0.997 \\
\hline IPMW post & 0.991 \\
\hline ABB Right pre (M1) & 0.979 \\
\hline ABB Right post (M1) & 0.987 \\
\hline
\end{tabular}




\begin{tabular}{|l|c|}
\hline ABB Left pre (M1) & 0.897 \\
\hline ABB Left post (M1) & 0.969 \\
\hline ABB Right pre (PM1) & 0.987 \\
\hline ABB Right post (PM1) & 0.992 \\
\hline ABB Left pre (PM1) & 0.941 \\
\hline ABB Left post (PM1) & 0.993 \\
\hline DT Right pre (M1) & 0.959 \\
\hline DT Right post (M1) & 0.984 \\
\hline DT Left pre (M1) & 0.948 \\
\hline DT Left post (M1) & 0.980 \\
\hline DT Right pre (PM1) & 0.981 \\
\hline DT Right post (PM1) & 0.997 \\
\hline DT Left pre (PM1) & 0.989 \\
\hline DT Left post (PM1) & 0.996 \\
\hline BBT Right pre (M1) & 0.985 \\
\hline BBT Right post (M1) & 0.9987 \\
\hline BBT Left pre (M1) & 0.975 \\
\hline BBT Left post (M1) & 0.960 \\
\hline BBT Right pre (PM1) & 0.973 \\
\hline BBT Right post (PM1) & 0.933 \\
\hline BBT Left pre (PM1) & \\
\hline BBT Left post (PM1) & \\
\hline Midpalatal Suture post (C) & \\
\hline Midpalatal Suture post (PM1) & \\
\hline
\end{tabular}




\begin{tabular}{|l|c|}
\hline Midpalatal Suture post (PM2 ) & 0.997 \\
\hline Midpalatal Suture post (M1) & 0.919 \\
\hline
\end{tabular}

\section{Skeletal, Dentoalveolar and Periodontal Changes in MSE Patients:}

\section{Total Expansion}

There was a significant increase in IMW between $\mathrm{T} 1(\mathrm{M}=40.9, \mathrm{SD}=3.6)$ and $\mathrm{T} 2$ $(\mathrm{M}=46.8, \mathrm{SD}=3.4) ; \mathrm{t}(15)=14.7, \mathrm{p}<.0001$. The total expansion achieved with MSE treatment was $5.9 \pm 1.6 \mathrm{~mm}$ at the M1 level. The percentage of skeletal expansion was $56 \%$ determined by the mean midpalatal suture expansion of $3.3 \pm 1.4 \mathrm{~mm}$ at the level of M1. The remaining $44 \%$ was attributed to dentoalveolar expansion. The mean of IPMW was increased to $34.3 \mathrm{~mm}$ in the patients assessed. Total expansion in PM1 level increased by a mean of $4.1 \mathrm{~mm}$ after using MSE.

2. Alveolar Bone Bending Angle

There was a significant increase in ABB angle in M1 and PM1 levels in both right and left sides between T2-T1 by mean of $6.4^{\circ}, 4.1^{\circ}, 4.8^{\circ}$, and $5.5^{\circ}$, respectively.

\section{Dental Tipping Angle}

There was a significant increase in DT angle toward the buccal in M1 in both left $\left(\mathrm{M}=2.8^{\circ}\right)$ and right $\left(\mathrm{M}=4^{\circ}\right)$ sides, and also in $\mathrm{PM} 1$ in the right side $\left(\mathrm{M}=1.5^{\circ}\right)$ only. However, there was a statistically insignificant increase in DT angle toward the buccal in PM1 in the left side $\left(2 \cdot 2^{\circ}\right)$. 


\section{Buccal Bone Thickness}

There was a significant decrease in BBT for M1 and PM1 levels in both right and left sides by mean of $-0.7 \mathrm{~mm},-0.5 \mathrm{~mm},-0.4 \mathrm{~mm}$ and $-0.4 \mathrm{~mm}$, respectively.

5. Midpalatal Suture Opening

There was a significant separation $(\mathrm{mm})$ in midpalatal suture at the level of C, PM1, PM2 and M1 ranged from 1.3 to 7, 1.3-6.6, 1.4-6.1, and 1.8-6.1, respectively. This indicated parallel expansion along the length of the midpalatal suture.

According to the paired t-test results, patients using MSE showed significant changes in all skeletal, dentoalveolar and periodontal measurements except dental tipping in the left side for PM1 after using the MSE expander (Table2).

Table 2: Comparison of pre and post expansion measurements using MSE $(n=16)$

\begin{tabular}{|l|c|c|c|c|c|c|}
\hline & \multicolumn{2}{|c|}{ T1 } & \multicolumn{2}{c|}{ T2 } & \\
\cline { 2 - 6 } & Mean & SD & Mean & SD & T (df=15) \\
a & Pb \\
\hline (IMW) (mm) & 40.9 & 3.6 & 46.8 & 3.4 & 14.7 & $\begin{array}{c}<.0001 \\
* * *\end{array}$ \\
\hline (IPMW) (mm) & 30.2 & 2.7 & 34.3 & 3.1 & 7.6 & $\begin{array}{c}<.0001 \\
* * *\end{array}$ \\
\hline $\begin{array}{l}\text { Alveolar Bone } \\
\text { Bending Right (M1) } \\
\text { (degree) }\end{array}$ & 110.4 & 8.6 & 116.7 & 8.8 & 5.2 & $\begin{array}{c}.0001 \\
* * *\end{array}$ \\
\hline $\begin{array}{l}\text { Alveolar Bone } \\
\text { Bending Left (M1) } \\
\text { (degree) }\end{array}$ & 108.0 & 9.3 & 112.2 & 9.1 & 4.2 & $\begin{array}{c}.0009 \\
* * *\end{array}$ \\
\hline
\end{tabular}




\begin{tabular}{|c|c|c|c|c|c|c|}
\hline $\begin{array}{l}\text { Alveolar Bone } \\
\text { Bending Right } \\
\text { (PM1) (degree) }\end{array}$ & 121.9 & 11.1 & 126.7 & 10.2 & 3.6 & $.003^{* * *}$ \\
\hline $\begin{array}{l}\text { Alveolar Bone } \\
\text { Bending Left (PM1) } \\
\text { (degree) }\end{array}$ & 121.3 & 12.0 & 126.8 & 11.2 & 3.5 & $.004^{* *}$ \\
\hline $\begin{array}{l}\text { Dental Tipping Right } \\
\text { (M1) (degree) }\end{array}$ & 96.6 & 4.6 & 100.7 & 5.4 & 6.9 & $\begin{array}{l}<.0001 \\
* * *\end{array}$ \\
\hline $\begin{array}{l}\text { Dental Tipping Left } \\
\text { (M1) (degree) }\end{array}$ & 96.7 & 5.8 & 99.5 & 6.8 & 4.4 & $\begin{array}{l}.0005 \\
* * *\end{array}$ \\
\hline $\begin{array}{l}\text { Dental Tipping Right } \\
\text { (PM1) (degree) }\end{array}$ & 90.3 & 13.9 & 91.9 & 15.0 & 2.3 & $.04 *$ \\
\hline $\begin{array}{l}\text { Dental Tipping Left } \\
\text { (PM1) (degree) }\end{array}$ & 92.4 & 6.3 & 94.2 & 8.0 & 1.7 & .11 \\
\hline $\begin{array}{l}\text { Buccal Bone } \\
\text { Thickness Right } \\
\text { (M1) (mm) }\end{array}$ & 1.8 & 0.7 & 1.1 & 0.6 & -6.0 & $\begin{array}{l}.0001 \\
* * *\end{array}$ \\
\hline $\begin{array}{l}\text { Buccal Bone } \\
\text { Thickness Left (M1) } \\
\text { (mm) }\end{array}$ & 1.6 & 0.8 & 1.1 & 0.7 & -8.1 & $\begin{array}{c}<.0001 \\
* * *\end{array}$ \\
\hline $\begin{array}{l}\text { Buccal Bone } \\
\text { Thickness Right } \\
\text { (PM1) (mm) }\end{array}$ & 0.9 & 0.5 & 0.5 & 0.5 & -4.3 & $\begin{array}{l}.0009 \\
* * *\end{array}$ \\
\hline $\begin{array}{l}\text { Buccal Bone } \\
\text { Thickness Left } \\
\text { (PM1) (mm) }\end{array}$ & 0.8 & 0.4 & 0.4 & 0.3 & -8.3 & $\begin{array}{l}<.0001 \\
* * *\end{array}$ \\
\hline $\begin{array}{l}\text { Midpalatal Suture } \\
\text { (C) }(\mathbf{m m})\end{array}$ & 0 & $\overline{0}$ & 4.1 & 1.8 & 9.2 & $\begin{array}{c}.0001 \\
* * *\end{array}$ \\
\hline $\begin{array}{l}\text { Midpalatal Suture } \\
\text { (PM1) (mm) }\end{array}$ & 0 & 0 & 3.8 & 1.8 & 8.2 & $\begin{array}{l}<.0001 \\
* * *\end{array}$ \\
\hline $\begin{array}{l}\text { Midpalatal Suture } \\
\text { (PM1 ) (mm) }\end{array}$ & 0 & 0 & 3.5 & 1.6 & 8.5 & $\begin{array}{l}<.0001 \\
* * *\end{array}$ \\
\hline
\end{tabular}




\begin{tabular}{|l|l|l|l|l|l|c|}
\hline $\begin{array}{l}\text { Midpalatal Suture } \\
\text { (M1) (mm) }\end{array}$ & 0 & 0 & 3.3 & 1.4 & 8.7 & $\begin{array}{c}<.0001 \\
* * *\end{array}$ \\
\hline
\end{tabular}

${ }^{a} \mathrm{~T}$-value from paired $\mathrm{t}$ test. $\mathrm{df}=$ degree of freedom

${ }^{\mathrm{b}} \mathrm{P}$-value from paired t test. ${ }^{*} \mathrm{p}<.05, * * \mathrm{p}<.01, * * * \mathrm{p}<.001$

\section{Skeletal, Dentoalveolar and Periodontal Changes in BAME Patients:}

\section{Total Expansion}

The mean of IMW was found to be $41.2 \mathrm{~mm}$ in the patients assessed. The total expansion achieved with BAME treatment was $4.7 \pm 2.7 \mathrm{~mm}$. The percentage of skeletal expansion was $83 \%$ and the dentoalveolar expansion was $17 \%$. There was a significant increase in IPMW between $\mathrm{T} 1(\mathrm{M}=25.7, \mathrm{SD}=2.2)$ and $\mathrm{T} 2(\mathrm{M}=30.4, \mathrm{SD}=2.4) ; \mathrm{t}(15)=14.5$, $\mathrm{p}<.0001$. Total expansion for PM1 of patients increased by mean of $4.7 \mathrm{~mm}$ after using the BAME expander.

2. Alveolar Bone Bending angle

There was a significant increase in ABB angle in $\mathrm{M} 1$ and PM1 in both right and left sides between $\mathrm{T} 2-\mathrm{T} 1$ by mean of $3.9^{\circ}, 5.3^{\circ}, 4.4^{\circ}$ and $4.1^{\circ}$, respectively.

3. Dental Tipping Angle

There was insignificant increase in DT angle toward the buccal in M1 in both right and left sides between $\mathrm{T} 2-\mathrm{T} 1$ by mean of $0.5^{\circ}$, and $0.5^{\circ}$, respectively. However, there was a significant decrease in DT angle toward the palate in PM1 in the right side $\left(\mathrm{M}=-1.4^{\circ}\right)$, but it was insignificant in the left side $\left(M=-0.7^{\circ}\right)$. 


\section{Buccal Bone Thickness}

There was a significant decrease in BBT for M1 and PM1 in both right and left sides by a mean of $-0.2 \mathrm{~mm},-0.1 \mathrm{~mm}$ and $-0.1 \mathrm{~mm}$, respectively. However, there was an insignificant decrease in BBT on the left side for $\mathrm{M} 1\left(\mathrm{M}=-0.1^{\circ}\right)$.

\section{Midpalatal Suture Opening}

There was a significant separation $(\mathrm{mm})$ in midpalatal suture at the level of C, PM1, PM2 and M1 ranged from 1.3 to $6.7,1.8-6.5,2.3-6.1$, and 1.6-5.6, respectively. This indicated parallel expansion along the length of the midpalatal suture.

According to the paired t-test results, patient using BAME expander showed significant changes in most of the skeletal, dentoalveolar and periodontal measurements except dental tipping right and left for M1, dental tipping left for PM1, buccal bone thickness left for M1 (Table 3).

Table 3: Comparison of pre and post expansion measurements using BAME $(n=18)$

\begin{tabular}{|c|c|c|c|c|c|c|}
\hline & & & T2 & & & \\
\hline & Mean & SD & Mean & SD & $\begin{array}{c}\mathrm{T} \\
(\mathrm{df}=17)^{\mathrm{a}}\end{array}$ & $\mathbf{P}^{\mathbf{b}}$ \\
\hline (IMW) & 36.5 & 2.8 & 41.2 & 3.3 & 14 & $<.0001 * * *$ \\
\hline (IPMW) & 25.7 & 2.2 & 30.4 & 2.4 & 14.5 & $<.0001 * * *$ \\
\hline $\begin{array}{l}\text { Alveolar Bone } \\
\text { Bending Right } \\
\text { (M1) }\end{array}$ & 103.6 & 5.9 & 107.4 & 6.6 & 3.6 & $.002 * *$ \\
\hline $\begin{array}{l}\text { Alveolar Bone } \\
\text { Bending Left } \\
\text { (M1) }\end{array}$ & 103.6 & 5.9 & 108.9 & 7.3 & 4.1 & $.0008 * * *$ \\
\hline
\end{tabular}




\begin{tabular}{|l|c|c|c|c|c|c|}
\hline $\begin{array}{l}\text { Alveolar Bone } \\
\text { Bending Right } \\
\text { (PM1) }\end{array}$ & 120.8 & 12.6 & 125.2 & 11.7 & 3.8 & $.002^{* *}$ \\
\hline $\begin{array}{l}\text { Alveolar Bone } \\
\text { Bending Left } \\
\text { (PM1) }\end{array}$ & 118.6 & 10.8 & 123.0 & 13.2 & 2.7 & $.02^{*}$ \\
\hline $\begin{array}{l}\text { Dental Tipping } \\
\text { Right (M1) }\end{array}$ & 94.3 & 6.0 & 94.8 & 4.3 & 0.5 & .6 \\
\hline $\begin{array}{l}\text { Dental Tipping } \\
\text { Left (M1) }\end{array}$ & 96.5 & 6.9 & 97.0 & 5.2 & 0.7 & .5 \\
\hline $\begin{array}{l}\text { Dental Tipping } \\
\text { Right (PM1) }\end{array}$ & 91.2 & 4.2 & 89.8 & 4.5 & -2.3 & $.04^{*}$ \\
\hline $\begin{array}{l}\text { Dental Tipping } \\
\text { Left (PM1) }\end{array}$ & 90.7 & 3.9 & 90.0 & 3.8 & -1.2 & .27 \\
\hline $\begin{array}{l}\text { Buccal Bone } \\
\text { Thickness Right } \\
\text { (M1) }\end{array}$ & 1.2 & 0.5 & 0.9 & 0.5 & -3.6 & $.002^{* *}$ \\
\hline $\begin{array}{l}\text { Buccal Bone } \\
\text { Thickness Left } \\
\text { (M1) }\end{array}$ & 1.0 & 0.5 & 0.9 & 0.6 & -1.7 & .12 \\
\hline $\begin{array}{l}\text { Buccal Bone } \\
\text { Thickness Right } \\
\text { (PM1) }\end{array}$ & 0.6 & 0.3 & 0.5 & 0.3 & -2.9 & $.01^{*}$ \\
\hline $\begin{array}{l}\text { Buccal Bone } \\
\text { Thickness Left } \\
\text { (PM1) }\end{array}$ & 0.7 & 0.3 & 0.5 & 0.3 & -2.9 & $.009^{* *}$ \\
\hline $\begin{array}{l}\text { Midpalatal } \\
\text { Suture (C) }\end{array}$ & 0 & 0 & 4.2 & 2.3 & 15.0 & $<.0001^{* * *}$ \\
\hline $\begin{array}{l}\text { Midpalatal } \\
\text { Suture (PM1) }\end{array}$ & 0 & & & & & \\
\hline $\begin{array}{l}\text { Midpalatal } \\
\text { Suture (PM2 ) }\end{array}$ & 0.4 & & & & & \\
\hline
\end{tabular}




\begin{tabular}{|l|l|l|l|l|l|l|}
\hline $\begin{array}{l}\text { Midpalatal } \\
\text { Suture (M1) }\end{array}$ & 0 & 0 & 3.9 & 1.2 & 12.9 & $<.0001^{* * *}$ \\
\hline
\end{tabular}

${ }^{\mathrm{a}} \mathrm{T}$-value from paired $\mathrm{t}$ test. $\mathrm{df}=$ degree of freedom

${ }^{\mathrm{b}} \mathrm{P}$-value from paired $\mathrm{t}$ test. ${ }^{*} \mathrm{p}<.05,{ }^{* *} \mathrm{p}<.01,{ }^{* * *} \mathrm{p}<.001$

\section{Comparison between the Hybrid and BAME study groups:}

Both study groups showed decreases in BBT at the level of M1 and PM1. However, the BAME group experienced significantly less buccal bone loss than the MSE group for both the M1 and PM1 $(\mathrm{P}<.05)$. Molar root inclination measurements from the MSE group demonstrated a mean buccal crown tipping of $3.5^{\circ}$, whereas the BAME group produced $0.5^{\circ}$ of buccal crown tipping. Premolar root angulation changes revealed $1.7^{\circ}$ buccal and $1^{\circ}$ of lingual crown tipping in the hybrid and BAME groups, respectively. The differences between the two groups were significant ( $\mathrm{P}$ $<.05)$.

Results of two-sample t-test showed there were significant difference between the MSE and the BAME between (T2-T1) in dental tipping and buccal bone thickness for M1 and PM1 in both right and left sides (Table 4). 
Table 4: Comparison of difference (T2-T1) measurements between MSE and BAME

\begin{tabular}{|l|c|c|c|c|c|c|}
\hline & \multicolumn{2}{|c|}{$\begin{array}{l}\text { MSE } \\
(\mathbf{n}=\mathbf{1 6})\end{array}$} & $\begin{array}{c}\text { BAME } \\
(\mathbf{n = 1 8})\end{array}$ & \multirow{2}{*}{ P $^{\mathbf{b}}$} \\
\cline { 2 - 6 } & Mean & SD & Mean & SD & \\
\hline TE (M1) & 5.9 & 1.6 & 4.7 & 2.7 & 1.38 & .19 \\
\hline TE (PM1) & 4.1 & 2.1 & 4.7 & 1.4 & -1.08 & .29 \\
\hline ABB Right (M1) & 6.4 & 4.9 & 3.9 & 4.5 & 1.54 & .13 \\
\hline ABB Left (M1) & 4.1 & 4.0 & 5.3 & 5.5 & -0.70 & .49 \\
\hline ABB Right (PM1) & 4.8 & 5.0 & 4.4 & 4.9 & 0.26 & .80 \\
\hline ABB Left (PM1) & 5.5 & 6.0 & 4.1 & 6.1 & 0.65 & .52 \\
\hline DT Right (M1) & 4.0 & 2.3 & 0.4 & 3.5 & 3.45 & $.002^{* *}$ \\
\hline DT Left (M1) & 2.8 & 2.5 & 0.5 & 3.0 & 2.42 & $.02^{*}$ \\
\hline DT Right (PM1) & 1.5 & 2.5 & -1.4 & 2.6 & 3.20 & $.003^{* *}$ \\
\hline DT Left (PM1) & 2.2 & 4.7 & -0.7 & 2.4 & 2.04 & .06 \\
\hline BBT Right (M1) & -0.7 & 0.4 & -0.2 & 0.3 & -3.44 & $.002^{* *}$ \\
\hline BBT Left (M1) & -0.5 & 0.2 & -0.1 & 0.3 & -4.37 & $.0001^{* * *}$ \\
\hline BBT Right (PM1) & -0.4 & 0.3 & -0.1 & 0.1 & -3.21 & $.003^{* *}$ \\
\hline BBT Left (PM1) & -0.3 & 0.2 & -0.1 & 0.2 & -2.95 & $.007^{* *}$ \\
\hline Midpalatal Suture (C) & 4.1 & 1.8 & 4.8 & 1.3 & -1.3 & .20 \\
\hline Midpalatal Suture (PM1) & 3.8 & 1.8 & 4.4 & 1.3 & -1.18 & .25 \\
\hline Midpalatal Suture (PM1) & 3.5 & 1.6 & 4.2 & 1.2 & -1.41 & .17 \\
\hline Midpalatal Suture (M1) & 3.3 & 1.4 & 3.9 & 1.2 & -1.17 & .25 \\
\hline
\end{tabular}

${ }^{a} \mathrm{~T}$-value from two independent sample $\mathrm{t}$ test. $\mathrm{df}=$ degree of freedom

${ }^{\mathrm{b}} \mathrm{P}$-value from two sample $\mathrm{t}$ test. ${ }^{*} \mathrm{p}<.05, * * \mathrm{p}<.01, * * * \mathrm{p}<.00$ 


\section{CHPTER 5: DISCUSSION}

The results of this study show that both types of MARPE appliances are effective in achieving separation of the midpalatal suture and correcting maxillary transverse discrepancies in young patients. This finding agrees with the results published by previous studies. ${ }^{50,35,65,66}$ Most of the subjects demonstrated successful maxillary expansion, evident by the opening of the midpalatal suture. The total amount of expansion varied from study to study due to the type of appliance, duration of treatment, and the rate of screw activations. In the literature, the range of expansion varied from $4.2 \mathrm{~mm}$ to $8 \mathrm{~mm} .^{66}$

In this study, total expansion at the M1 level was $2.9 \mathrm{~mm}$ to $7.9 \mathrm{~mm}$ in the MSE group, and $1.8 \mathrm{~mm}$ to $8.6 \mathrm{~mm}$ in the BAME group. This study showed that the skeletal contribution was $56 \%$ in the MSE group, and $83 \%$ in the BAME group. This is in agreement with those reported by Oh et el. which showed $73 \%$ in the MSE group, and $81 \%$ in the BAME group. ${ }^{67}$ The skeletal gain in the BAME sample of this study was higher than the $50 \%$ reported by Profitt; $40 \%$ by Kartalian, ${ }^{68}$ and $55 \%$ reported by Garrett. ${ }^{34}$ However, in these studies, the authors used conventional instead of bone-anchored appliances to expand the maxilla in younger patients. In other studies using the MSE and BAME appliances, the percentage skeletal contribution increased to $59 \%$ reported by Zong et al, with MSE, ${ }^{11}$ and $68 \%$ reported by Celenk-koca et al, ${ }^{35}$ with BAME. The most probable reason could be due to the nature of the design of MARPE. The MSE appliance uses bi-cortical engagement with longer implants offering greater skeletal anchorage. ${ }^{50}$

The pattern of midpalatal suture separation observed with both types of MARPE appliances in this study was found to be parallel in the axial view. The amount of suture opening at the C, PM1, 
PM2 and M1 levels differed from each other by no more than $0.5 \pm 0.2 \mathrm{~mm}$. This indicated that sutural expansion at the level of the palate was rather uniform anteroposteriorly, which agrees with the findings of other previous authors. ${ }^{64,18,67}$ However, Lin et al. ${ }^{69}$ demonstrated that midpalatal suture opening occurred in a triangular pattern super inferiorly, with the least increase at the nasal floor and the greatest increase at the hard palate. These contrasting findings may be due to the different amounts of appliance activation performed in each study, anteroposterior position of miniscrews placement in the maxilla, or ineffective expansion near zygomaxillary and nasomaxillary sutures. ${ }^{11}$

Buccal rotation or bending of the segments occurs throughout the arch, but the amount is greater from posterior to anterior. ${ }^{34}$ This is most likely the reason for dental tipping in expansion patients even without tooth anchorage (e.g. BAME) and may also explain the angulation changes of the M1 and PM1. ${ }^{10}$ This buccal rolling phenomenon had been expressed by the decrease of the external inclination angle of the M1 and PM1. ${ }^{4}$ There was insignificant different in the alveolar bone bending between both MARPE groups. These findings coincided with those of Garib et al, ${ }^{70}$ and Mosleh et al, ${ }^{4}$

Despite the fact that both types of MARPE appliances were skeletally anchored, there was evidence of buccal dental tipping at the levels of M1 and PM1 in both groups. The crown tipping can be due to the play between the miniscrew and the insertion slot of the miniscrew as reported by Carlson et al. ${ }^{18}$ In other words, this might be related to the force application away from the center of resistance of the anchoring units and to the outward rotational movement of the two palatal shelves. ${ }^{4}$ In the current study, tipping of posterior teeth in BAME group $\left(0.5^{\circ}\right.$ for M1, and $-1^{\circ}$ for PM1) was significantly reduced in comparison with the MSE group (3.4 for M1, and $1.9^{\circ}$ 
for PM1). The decrease in the amount of buccal dental tipping of M1 is consistent with previous MARPE studies. ${ }^{4,50,35,67}$ Uprighting of the M1 and PM1 could be explained by the absence of a buccal force acting on the crowns and increased apical separation of the maxillary suture in the BAME group, leading to a more upright crown inclination relative to the nasal floor. Moreover, heavy stainless-steel wires used in the final stages of comprehensive orthodontic treatment would introduce negative torque to the posterior teeth, restoring the ideal buccolingual inclinations of the teeth and possibly decreasing the amount of expansion previously gained by tipping of the posterior teeth buccally. ${ }^{26}$

Decreased buccal bone thickness and bony dehiscence are frequently reported in the literature as a result of rapid maxillary expansion due to osteoclastic resorption as teeth move through the buccal plate. ${ }^{35}$ Previous studies recorded a reduction in BBT of the anchored teeth ranging from 0.2 to $0.5 \mathrm{~mm}^{71}$ and from 0.73 to $1.25 \mathrm{~mm}^{72}$. In this study, the buccal bone reduction was $(0.6 \mathrm{~mm}$ for M1, and $0.4 \mathrm{~mm}$ for PM1) in MSE group, while in BAME group BBT was (0.2 mm for M1, and $0.1 \mathrm{~mm}$ for PM1). Current results indicate that changes in the buccal bone thickness occurred significantly less in BAME group compared to MSE group. Lee et $a l,{ }^{73}$ suggested that BAME may be better indicated for growing children whose palatal bones may exhibit less resistance than those in adults, technically eliminating the need for banding, and additional laboratory work. To prevent these side effects on permanent teeth, miniscrew-supported appliances or appliances anchored to deciduous teeth were proposed as valid alternative protocols for rapid maxillary expansion. ${ }^{72}$ However, a 6-month retention period was enough for the recovery of the buccal and lingual bone plates thickness. ${ }^{66}$ 
In addition, a finite elements analysis study about the differences of stress distribution on maxillary expanders, suggested that the potential benefits for a clinician to use MARPE could be possible alleviation of stress distribution on the buccal bone, parallel split of the palatine suture, and minimized tipping of the teeth. ${ }^{74}$ Another finite elements study found that the BAME did not show any possible side effects on the buccal plate, but the force transduction was very limited even within the midpalatal sutural area. By combining the conventional RPE and four miniscrews, in view of the displacement pattern, the MSE secured significant expansion of the anchor teeth to the buccal side with reduced tipping, compared to the conventional RPE. The teeth displacement was not remarkable with BAME. Conclusively, incorporation of four miniscrews was considered reasonable for even dissipation of the pressure along the suture and for the reduction of pressure on the buccal plate. ${ }^{73}$

The current study has several limitations. The small sample size and the lack of short-term (6 months), and long-term (5 years) follow-up after expansion limit the ability to draw a definitive conclusion between the two appliance designs. In addition, other variables such as the expansion appliance design, activation protocol, methods of evaluating expansion effects, and biological variability may influence patient response to appliance therapy. 


\section{CHPTER 6: SUMMARY AND CONCLUSION}

\section{Summary}

The rationale for this study is to gain a better understanding of the skeletal, dentoalveolar and periodontal changes between two types of MARPE, the MSE and the BAME, using CBCT.

This study was conducted in collaboration with the Department of Orthodontics at Wuhan and Tufts Universities. A total of 34 subjects with pre- and post-expansion CBCT scans were evaluated. All DICOM files were analyzed using Dolphin 3D Imaging 11.95 software. CBCT images were used to find the amount of midpalatal suture opening, total expansion, alveolar bone bending angle, dental tipping angle, and buccal bone thickness at the first molar and first premolar levels.

Based on results discussed in Chapter IV, the following null hypotheses were rejected:

- There is no midpalatal suture opening in patients treated with expander appliance among the two types of expanders

- There is no significant difference in the dental tipping angle between T1 and T2 measured at PM1 and M1 between the two types of expanders

- There is no significant difference in the buccal bone thickness between $\mathrm{T} 1$ and $\mathrm{T} 2$ measured at PM1 and mesiobuccal root of the M1 between the two types of expanders

The following null hypotheses were accepted:

There is no significant differences in midpalatal suture opening in the axial plane at C, PM1, PM2, and M1 between the two types of expanders at palatal floor

- There is no significant differences in midpalatal suture expansion pattern in the axial plane between the two types of expanders 
- There is no significant difference in the amount of total expansion between T1 and T2 measured at PM1 and M1 between the two types of expanders

- There is no significant difference in the alveolar bone bending angle between T1 and T2 measured at PM1 and M1 between the two types of expanders

Summary:

1. Midpalatal suture separated in $100 \%$ of subjects.

2. Pattern of midpalatal suture opening was parallel in axial view in both groups.

3. Contribution to total expansion in MSE include $56 \%$ skeletal, and $44 \%$ dentoalveolar expansion, while in BAME include $83 \%$ skeletal, and $17 \%$ dentoalveolar expansion. 4. Both types had a significant dental tipping. However, the dental tipping was greater in MSE group $\left(3.4^{\circ}\right.$ for $\mathrm{M} 1$, and $1.9^{\circ}$ for PM1), compared to BAME group (0.5 for M1, and $-1^{\circ}$ for PM1) which could be decompensated with orthodontic uprighting.

5. Both types had a significant reduction in buccal bone thickness. However, the bone loss was greater in MSE group (0.6 mm for M1, and $0.4 \mathrm{~mm}$ for PM1), compared to BAME group (0.2 mm for M1, and $0.1 \mathrm{~mm}$ for PM1) which may recover overtime with bone apposition.

\section{Conclusions}

1. The use of BAME result in greater skeletal effects and less dentoalveolar side effects including less dental tipping and less buccal bone reduction compared to the use of MSE.

2. Both types of MARPE can be a clinically acceptable, nonsurgical treatment option for correcting mild to moderate maxillary transverse discrepancies in growing patients.

3. BAME is more favorable in cases where dentoalveolar changes are undesirable. 


\section{CHAPTER 7: RECOMMENDATIONS FOR FUTURE RESEARCH}

The clinically relevant findings of this study warrant future research in this area. This study should be repeated with a larger sample size and standardized for the following, including but not limited to:

1. Appliance placement anterioposteriorly along the palate

2. Number of teeth selected for appliance anchorage

3. The amount of appliance activation

4. CVM stage or midpalatal suture maturation stage or both

Additionally, reliable assessment methods should be established for assessment of microimplant stability in terms of mobility detection in order to evaluate if skeletal anchorage has been compromised during active expansion. Long-term follow-up evaluations of the sample should also be conducted to gain an understanding of the stability of the skeletal, dentoalveolar and periodontal effects for both types of MARPE, and the relapse potential of this technique in growing patients by comparing it to a control group treated with conventional maxillary expander appliance. 


\section{References:}

1. da Silva Filho OG, Santamaria Jr. M, Filho LC. Epidemiology of Posterior Crossbite in the Primary Dentition. J. Clin. Pediatr. Dent. 2007;32(1):73-8. Available at: http://jocpd.org/doi/10.17796/jcpd.32.1.h53g027713432102.

2. Adkins MD, Nanda RS, Currier GF. Arch perimeter changes on rapid palatal expansion. Am. J. Orthod. Dentofac. Orthop. 1990;97(3):194-9. Available at: https://linkinghub.elsevier.com/retrieve/pii/S0889540605800514. 3. Garrett BJ, Caruso JM, Rungcharassaeng K, Farrage JR, Kim JS, Taylor GD. Editor's Summary, Q \&amp; A, Reviewer's Critique. Am. J. Orthod. Dentofac. Orthop. 2008;134(1):8-9. Available at: https://linkinghub.elsevier.com/retrieve/pii/S0889540608006136.

4. Mosleh MI, Kaddah MA, Abd ElSayed FA, ElSayed HS. Comparison of transverse changes during maxillary expansion with 4-point bone-borne and tooth-borne maxillary expanders. Am. $J$. Orthod. Dentofac. Orthop. 2015;148(4):599-607. Available at: https://linkinghub.elsevier.com/retrieve/pii/S0889540615007775. 5. Kircelli BH, Pektaş ZO, Uçkan S. Orthopedic protraction with skeletal anchorage in a patient with maxillary hypoplasia and hypodontia. Angle Orthod. 2006;76(1):156-63. Available at: http://www.ncbi.nlm.nih.gov/pubmed/16448286.

6. Harzer W, Schneider M, Gedrange T, Tausche E. Direct bone placement of the hyrax fixation screw for surgically assisted rapid palatal expansion (SARPE). J. Oral Maxillofac. Surg. 2006;64(8):1313-7. Available at: http://www.ncbi.nlm.nih.gov/pubmed/16860233.

7. Tausche E, Hansen L, Hietschold V, Lagravère MO, Harzer W. Three-dimensional evaluation of surgically assisted implant bone-borne rapid maxillary expansion: a pilot study. Am. J.

Orthod. Dentofacial Orthop. 2007;131(4 Suppl):S92-9. Available at:

http://www.ncbi.nlm.nih.gov/pubmed/17448393.

8. Lee K-J, Park Y-C, Park J-Y, Hwang W-S. Miniscrew-assisted nonsurgical palatal expansion before orthognathic surgery for a patient with severe mandibular prognathism. Am. J. Orthod.

Dentofac. Orthop. 2010;137(6):830-9. Available at:

https://linkinghub.elsevier.com/retrieve/pii/S0889540610001125.

9. Garib DG, Navarro RDL, Francischone CE, Oltramari PVP. Rapid maxillary expansion using palatal implants. J. Clin. Orthod. 2008;42(11):665-71. Available at:

http://www.ncbi.nlm.nih.gov/pubmed/19075382.

10. Lagravère MO, Carey J, Heo G, Toogood RW, Major PW. Transverse, vertical, and anteroposterior changes from bone-anchored maxillary expansion vs traditional rapid maxillary expansion: a randomized clinical trial. Am. J. Orthod. Dentofacial Orthop. 2010;137(3):304.e112; discussion 304-5. Available at: http://www.ncbi.nlm.nih.gov/pubmed/20197161.

11. Zong C, Tang B, Hua F, He H, Ngan P. Skeletal and dentoalveolar changes in the transverse dimension using microimplant-assisted rapid palatal expansion (MARPE) appliances. Semin. Orthod. 2019;25(1):46-59. Available at:

https://linkinghub.elsevier.com/retrieve/pii/S1073874619300064.

12. KRAUS BS. Prenatal growth and morphology of the human bony palate. J. Dent. Res. 39:1177-99. Available at: http://www.ncbi.nlm.nih.gov/pubmed/13754062.

13. Suzuki H, Moon W, Previdente LH, Suzuki SS, Garcez AS, Consolaro A. Miniscrew-assisted rapid palatal expander (MARPE): The quest for pure orthopedic movement. Dental Press $J$. Orthod. 2016;21(4):17-23.

14. Consolaro A. I n s I g h t O r t O d ô n t I c O. Dent. Press J Orthod 2011;1916(4):19-24. 
15. Latham RA, Burston WR. The postnatal pattern of growth at the sutures of the human skull. An histological survey. Dent. Pract. Dent. Rec. 1966;17(2):61-7. Available at:

http://www.ncbi.nlm.nih.gov/pubmed/4288317.

16. Melsen B. Palatal growth studied on human autopsy material. A histologic microradiographic study. Am. J. Orthod. 1975;68(1):42-54. Available at:

http://www.ncbi.nlm.nih.gov/pubmed/1056143.

17. Ennes J, Consolaro A. Sutura palatina mediana: avaliação do grau de ossificação em crânios humanos. Rev. Dent. Press Ortod. e Ortop. Facial 2004;9(5):64-73. Available at:

http://www.scielo.br/scielo.php?script=sci_arttext\&pid=S1415-

$54192004000500008 \& \operatorname{lng}=$ pt\&tlng=pt.

18. Carlson C, Sung J, McComb RW, MacHado AW, Moon W. Microimplant-assisted rapid palatal expansion appliance to orthopedically correct transverse maxillary deficiency in an adult. Am. J. Orthod. Dentofac. Orthop. 2016;149(5):716-28.

19. Nguyen UK, Tremont T, Martin C, Virginia W. Retrospective Evaluation of Skeletal, Dentoalveolar, and Periodontal Changes of Microimplant Assisted Rapid Palatal Expansion ( MARPE ) In Skeletally Matured Patients Thesis submitted to the School of Dentistry at West Virginia University in partial ful. 2017.

20. Zong C, Tang B, Hua F, He H, Ngan P. Skeletal and dentoalveolar changes in expansion ( MARPE ) appliances. Semin. Orthod. 2019;25(1):46-59. Available at:

https://doi.org/10.1053/j.sodo.2019.02.006.

21. Korkhaus G. Present orthodontic thought in Germany. Am. J. Orthod. 1960;46(3):187-206. Available at: https://linkinghub.elsevier.com/retrieve/pii/0002941660900816.

22. Handelman CS, Wang L, BeGole EA, Haas AJ. Nonsurgical Rapid Maxillary Expansion in Adults: Report on 47 Cases Using the Haas Expander. Angle Orthod. 2000;70(2):129-44.

23. Rungcharassaeng K, Caruso JM, Kan JYK, Kim J, Taylor G. Factors affecting buccal bone changes of maxillary posterior teeth after rapid maxillary expansion. Am. J. Orthod. Dentofac. Orthop. 2007;132(4):428.e1-428.e8.

24. Christie KF, Boucher N, Chung C-H. Effects of bonded rapid palatal expansion on the transverse dimensions of the maxilla: a cone-beam computed tomography study. Am. J. Orthod. Dentofacial Orthop. 2010;137(4 Suppl):S79-85. Available at:

http://www.ncbi.nlm.nih.gov/pubmed/20381765.

25. Pangrazio-Kulbersh V, Wine P, Haughey M, Pajtas B, Kaczynski R. Cone beam computed tomography evaluation of changes in the naso-maxillary complex associated with two types of maxillary expanders. Angle Orthod. 2012;82(3):448-57.

26. Akyalcin S, Schaefer JS, English JD, Stephens CR, Winkelmann S. A cone-beam computed tomography evaluation of buccal bone thickness following maxillary expansion. Imaging Sci. Dent. 2013;43(2):85-90. Available at: http://www.ncbi.nlm.nih.gov/pubmed/23807931.

27. Pangrazio-Kulbersh V, Jezdimir B, de Deus Haughey M, Kulbersh R, Wine P, Kaczynski R. CBCT assessment of alveolar buccal bone level after RME. Angle Orthod. 2013;83(1):110-6. Available at: http://www.ncbi.nlm.nih.gov/pubmed/22946618.

28. Brunetto M, Andriani J da SP, Ribeiro GLU, Locks A, Correa M, Correa LR. Threedimensional assessment of buccal alveolar bone after rapid and slow maxillary expansion: a clinical trial study. Am. J. Orthod. Dentofacial Orthop. 2013;143(5):633-44. Available at: http://www.ncbi.nlm.nih.gov/pubmed/23631965.

29. Baysal A, Karadede I, Hekimoglu S, et al. Evaluation of root resorption following rapid maxillary expansion using cone-beam computed tomography. Angle Orthod. 2012;82(3):488-94. 
Available at: http://www.angle.org/doi/10.2319/060411-367.1.

30. Akyalcin S, Alexander SP, Silva RM, English JD. Evaluation of three-dimensional root surface changes and resorption following rapid maxillary expansion: a cone beam computed tomography investigation. Orthod. Craniofac. Res. 2015;18 Suppl 1:117-26. Available at: http://www.ncbi.nlm.nih.gov/pubmed/25865540.

31. Xu X, Zhou J, Yang F, Wei S, Dai H. Using Micro-Computed Tomography to Evaluate the Dynamics of Orthodontically Induced Root Resorption Repair in a Rat Model. PLoS One 2016;11(3):e0150135. Available at: http://www.ncbi.nlm.nih.gov/pubmed/26930605.

32. Sun Z, Hueni S, Tee BC, Kim H. Mechanical strain at alveolar bone and circummaxillary sutures during acute rapid palatal expansion. Am. J. Orthod. Dentofac. Orthop.

2011;139(3):e219-28. Available at: http://dx.doi.org/10.1016/j.ajodo.2009.12.029.

33. Suzuki H, Moon W, Previdente LH, Suzuki SS, Garcez AS, Consolaro A. Miniscrew-assisted rapid palatal expander ( MARPE ): the quest for pure orthopedic movement. 2016;21(4):17-23. 34. Garrett BJ, Caruso JM, Rungcharassaeng K, Farrage JR, Kim JS, Guy D. Skeletal effects to the maxilla after rapid maxillary expansion assessed with cone-beam computed tomography. 2008:8-9.

35. Celenk-koca T, Ertan A, Hazar S, Harris L, English JD. Evaluation of miniscrew-supported rapid maxillary expansion in adolescents : A prospective randomized clinical trial.

2018;88(6):702-9.

36. Kapila SD ed. Cone Beam Computed Tomography in Orthodontics: Indications, Insights, and Innovations. Ames, USA: John Wiley \& Sons, Inc.; 2014. Available at:

http://doi.wiley.com/10.1002/9781118674888.

37. Pogrel MA, Kaban LB, Vargervik K, Baumrind S. Surgically assisted rapid maxillary

expansion in adults. Int. J. Adult Orthodon. Orthognath. Surg. 1992;7(1):37-41. Available at: http://www.ncbi.nlm.nih.gov/pubmed/1453038.

38. Anon. The Surgery of Oral and Facial Diseases and Malformations: Their Diagnosis and Treatment Including Plastic Surgical Reconstruction. J. Am. Med. Assoc. 1939;112(21):2199. Available at:

http://jama.jamanetwork.com/article.aspx?doi=10.1001/jama.1939.02800210093032.

39. Sankar Singaraju G, Chembeti D, Mandava P, Karunakar Reddy V, Kumar Shetty S, Ani

George S. Original Research Conflicts of Interest: None Source of Support: Nil A Comparative Study of Three Types of Rapid Maxillary Expansion Devices in Surgically Assisted Maxillary Expansion: A Finite Element Study.; 2015.

40. Koudstaal MJ, Smeets JBJ, Kleinrensink G-J, Schulten AJM, van der Wal KGH. Relapse and stability of surgically assisted rapid maxillary expansion: an anatomic biomechanical study. $J$.

Oral Maxillofac. Surg. 2009;67(1):10-4. Available at:

http://www.ncbi.nlm.nih.gov/pubmed/19070742.

41. Han UA, Kim Y, Park JU. Three-dimensional finite element analysis of stress distribution and displacement of the maxilla following surgically assisted rapid maxillary expansion. $J$.

Craniomaxillofac. Surg. 2009;37(3):145-54. Available at:

http://www.ncbi.nlm.nih.gov/pubmed/19028107.

42. Baccetti T, Franchi L, Cameron CG, McNamara JA. Treatment timing for rapid maxillary expansion. Angle Orthod. 2001;71(5):343-50. Available at:

http://www.ncbi.nlm.nih.gov/pubmed/11605867.

43. Asscherickx K, Govaerts E, Aerts J, Vande Vannet B. Maxillary changes with bone-borne surgically assisted rapid palatal expansion: A prospective study. Am. J. Orthod. Dentofacial 
Orthop. 2016;149(3):374-83. Available at: http://www.ncbi.nlm.nih.gov/pubmed/26926025. 44. Anon. No Title. Available at: http://jawsurgeryforums.com/index.php?topic=6415.15. 45. Liu SSY, Kyung HM, Buschang PH. Continuous forces are more effective than intermittent forces in expanding sutures. Eur. J. Orthod. 2010;32(4):371-80.

46. Hansen L, Tausche E, Hietschold V, Hotan T, Lagravère M, Harzer W. Skeletally-anchored rapid maxillary expansion using the Dresden Distractor. J. Orofac. Orthop. 2007;68(2):148-58. Available at: http://www.ncbi.nlm.nih.gov/pubmed/17372711.

47. Hartono N, Soegiharto BM. The difference of stress distribution of maxillary expansion using rapid maxillary expander ( RME) and maxillary skeletal expander ( MSE ) — a finite element analysis. 2018.

48. Wilmes B, Nienkemper M, Drescher D. Application and effectiveness of a mini-implant- and tooth-borne rapid palatal expansion device: the hybrid hyrax. World J. Orthod. 2010;11(4):32330. Available at: http://www.ncbi.nlm.nih.gov/pubmed/21490997.

49. Winsauer H, Walter A, Scherfler M, Ploder O. What are the limits of microimplant-assisted palatal expanders? Am. J. Orthod. Dentofac. Orthop. 2017;151(1):3-4.

50. Clement EA, Krishnaswamy NR. Skeletal and Dentoalveolar Changes after Skeletal Anchorage - assisted Rapid Palatal Expansion in Young Adults : A Cone Beam Computed Tomography Study. 2017.

51. Winsauer H, Walter A, Jaeschke D, Winsauer C, Muchitsch AP, Wendl B. Pure bone-borne palatal expander anchored on orthodontic mini-implants Micro-4 or Micro-6 Expander Ekspander podniebienny oparty na miniimplantach ortodontycznych. 2015:6-18.

52. Williams BJD, Currimbhoy S, Silva A, O'Ryan FS. Complications following surgically assisted rapid palatal expansion: a retrospective cohort study. J. Oral Maxillofac. Surg. 2012;70(10):2394-402. Available at: http://www.ncbi.nlm.nih.gov/pubmed/22516838.

53. Ludwig B, Baumgaertel S, Zorkun B, et al. Application of a new viscoelastic finite element method model and analysis of miniscrew-supported hybrid hyrax treatment. Am. J. Orthod.

Dentofacial Orthop. 2013;143(3):426-35. Available at:

http://www.ncbi.nlm.nih.gov/pubmed/23452978.

54. Handelman C. Palatal expansion in adults: The nonsurgical approach. Am. J. Orthod.

Dentofac. Orthop. 2011;140(4):462-8. Available at:

http://dx.doi.org/10.1016/j.ajodo.2011.07.002.

55. Weissheimer A, De Menezes LME, Mezomo M, Dias DM, De Lima EMS, Rizzatto SMD. Immediate effects of rapid maxillary expansion with Haas-type and hyrax-type expanders: A randomized clinical trial. Am. J. Orthod. Dentofac. Orthop. 2011;140(3):366-76.

56. Gautam P, Valiathan A, Adhikari R. Stress and displacement patterns in the craniofacial skeleton with rapid maxillary expansion: A finite element method study. Am. J. Orthod.

Dentofac. Orthop. 2007;132(1):5.e1-5.e11.

57. Date P. UCLA UCLA Electronic Theses and Dissertations Terahertz Quantum-Cascade Transmission-Line. 2012:1650-829.

58. McCrillis JM, Haskell J, Haskell BS, et al. Obstructive Sleep Apnea and the Use of Cone Beam Computed Tomography in Airway Imaging: A Review. Semin. Orthod. 2009;15(1):63-9. Available at: http://dx.doi.org/10.1053/j.sodo.2008.09.008.

59. dos Reis Zinsly S, de Moraes LC, de Moura P, Ursi W. Assessment of pharyngeal airway space using Cone-Beam Computed Tomography. Dental Press J. Orthod. 2010;15(5):150-8. Available at: http://www.scopus.com/inward/record.url?eid=2-s2.0-

84858275054\&partnerID=40\&md5=92d8d73dd98684ea404be7d58bf441c4. 
60. Anon. CBCT. Available at:

https://en.wikipedia.org/wiki/Cone_beam_computed_tomography.

61. Gribel BF, Gribel MN, Frazão DC, McNamara JA, Manzi FR. Accuracy and reliability of craniometric measurements on lateral cephalometry and 3D measurements on CBCT scans. Angle Orthod. 2011;81(1):28-37.

62. Patcas R, Müller L, Ullrich O, Peltomäki T. Accuracy of cone-beam computed tomography at different resolutions assessed on the bony covering of the mandibular anterior teeth. Am. J. Orthod. Dentofac. Orthop. 2012;141(1):41-50.

63. Martins LS, Liedke GS, Heraldo LD da S, et al. Airway volume analysis: is there a correlation between two and three-dimensions? Eur. J. Orthod. 2018;40(3):262-7. Available at: https://academic.oup.com/ejo/article/40/3/262/4210608.

64. Ngan P, Nguyen UK, Nguyen T, Tremont T, Martin C. Skeletal, Dentoalveolar, and Periodontal Changes of Skeletally Matured Patients with Maxillary Deficiency Treated with Microimplant-assisted Rapid Palatal Expansion Appliances: A Pilot Study. APOS Trends Orthod. 2018;8:71. Available at: https://apospublications.com/skeletal-dentoalveolar-andperiodontal-changes-of-skeletally-matured-patients-with-maxillary-deficiency-treated-withmicroimplant-assisted-rapid-palatal-expansion-appliances-a-pilot-study/.

65. Lin L, Ahn H, Kim S, Moon S, Kim S, Nelson G. Tooth-borne vs bone-borne rapid maxillary expanders in late adolescence. 2015;85(2).

66. Ahmad S, View A, Alkadri SA, Cristina M, Pollmann F. Bone-Borne versus Tooth-Borne Rapid Palatal Expansion (RPE) Treatment in Mixed Dentition; Literature Review.; 2018. Available at: https://www.researchgate.net/publication/325020356.

67. Oh H, Park J, Lagravere-Vich MO. Comparison of traditional RPE with two types of microimplant assisted RPE: CBCT study. Semin. Orthod. 2019;25(1):60-8. Available at:

https://linkinghub.elsevier.com/retrieve/pii/S1073874619300076.

68. Kartalian A, Gohl E, Adamian M, Enciso R. Cone-beam computerized tomography evaluation of the maxillary dentoskeletal complex after rapid palatal expansion. Am. J. Orthod. Dentofac. Orthop. 2010;138(4):486-92. Available at:

http://dx.doi.org/10.1016/j.ajodo.2008.10.025.

69. Lin L, Ahn HW, Kim SJ, Moon SC, Kim SH, Nelson G. Tooth-borne vs bone-borne rapid maxillary expanders in late adolescence. Angle Orthod. 2015;85(2):253-62.

70. Antonio GGJFCHGJMRFR. Rapid Maxillary Expansion — Tooth Tissue-Borne Versus

Tooth-Borne Expanders : A Computed Tomography Evaluation of Dentoskeletal Effects. 2005:3-5.

71. Fabiana Ballantia; Roberta Lionea; Ezio Fanuccib; Lorenzo Franchic; Tiziano Baccettic; paola cozza. Immediate and Post-Retention Effects of Rapid Maxillary Expansion Investigated by Computed Tomography in Growing Patients. 2008. Available at:

https://www.angle.org/doi/pdf/10.2319/012008-35.1.

72. Digregorio MV, Fastuca R, Zecca PA, Caprioglio A, Lagravère MO. Buccal bone plate thickness after rapid maxillary expansion in mixed and permanent dentitions. Am. J. Orthod. Dentofac. Orthop. 2019;155(2):198-206.

73. Lee K-J, Choi S-H, Choi T-H, Shi K-K, Keum B-T. Maxillary transverse expansion in adults: Rationale, appliance design, and treatment outcomes. Semin. Orthod. 2018;24(1):52-65. 74. Hartono N, Soegiharto BM, Widayati R. The difference of stress distribution of maxillary expansion using rapid maxillary expander (RME) and maxillary skeletal expander (MSE) - a finite element analysis. Prog. Orthod. 2018;19(1). 


\section{APPENDICES}

\section{Appendix A:}

\section{WestVirginiaUniversity. \\ OFFICE OF HUMAN RESEARCH PROTECTIONS \\ 896 Chestnut Ridge Road Morgantown, WV 26506}

Acknowledgement of Exemption

$11 / 08 / 2019$

To: Peter Ngan

From: WVU Office of Research Integrity \& Compliance

Protocol Type: Exempt

Submission Type: Initial

Funding: N/A

WVU Protocol \#: 1909722030

Protocol Title: Comparison of Skeletal and Dentoalveolar Changes During Maxillary Expansion with Bone-borne and Hybrid Expanders
Approval Date: 11/08/2019

Expiration Date: 11/07/2024

The West Virginia University Institutional Review Board has reviewed your submission of Exempt protocol 1909722030. Additional details regarding the review are below:

- This research study was granted an exemption in accordance with Research on existing data, documents, records, pathological specimens, or diagnostic specimens [45 CFR 46.101(4)]. In accordance with the Health Insurance Portability and Accountability Act, a waiver of research authorization has been granted. Please fulfill the subject accounting requirements associated with the granting of this waiver. All exemptions are only good for three years. If this research extends more than three years beyond the approved date, then the researcher will have to request another exemption. The following documents have been acknowledged for use in this study and are available in the WVU+kc system

The following documents were reviewed and approved for use as part of this submission. Only the documents listed below may be used in the research. Please access and print the files in the Notes \& Attachments section of your approved protocol.

- 1.PNG

- Mohamad proposal 09-25-2019.docx

Protocol $=1909722030$

FWA: 00005078

IORG: 0000194
Phone: $304-293-7073$

Fax: 304-293-3098

Email: IRB@mail.wvu.edu 
- Permission from Tufts.pdf

- permession letter from China.pdf

\section{WVU IRB acknowledgement of protocol 1909722030 will expire on 11/07/2024.}

If the study is to continue beyond the expiration date, a renewal application must be submitted no later than two (2) weeks prior to expiration date. It is your responsibility to submit your protocol for renewal.

Once you begin your human subjects research, the following regulations apply:

1. Unanticipated or serious adverse events and/or side effects encountered in this research study must be reported to the IRB within five (5) days, using the Notify IRB action in the electronic protocol.

2. Any modifications to the study protocol should be submitted only if there will be an increase in risk to subjects accompanying the proposed change(s).

3. You may not use a modified information sheet until it has been reviewed and acknowledged by the WVU IRB prior to implementation.

The Office of Research Integrity and Compliance will be glad to provide assistance to you throughout the research process. Please feel free to contact us by phone, at 304.293 .7073 or by email at IRB@mail.wvu.edu.

Sincerely, 


\section{Appendix B:}

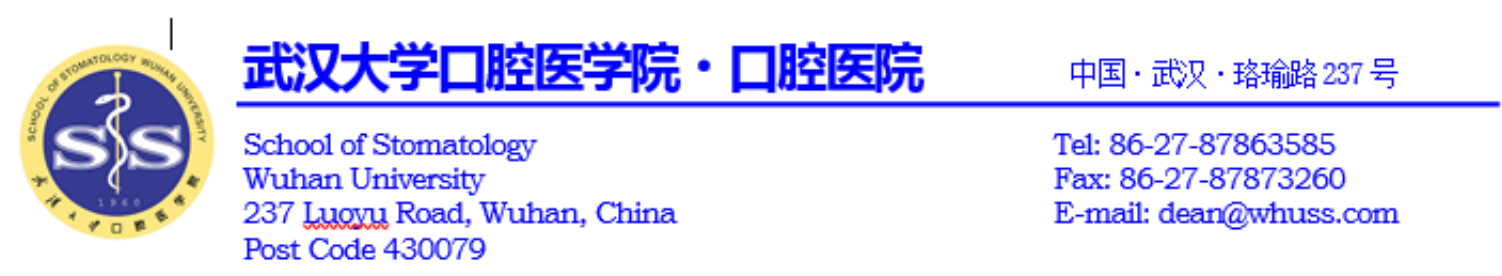

September 19, 2019

To: Dr. Peter Ngan

Professor and Chair

West Virginia University Department of Orthodontics

From: Professor Hong $\mathrm{He}$

Professor and Chair

Wuhan University School of Stomatology

Re: "Comparison of skeletal and dental changes between absolute and hybrid bone-borne maxillary expansion appliances" using conventional RPE as the control group"

Dear Sir/Madam,

The Wuhan University School of Stomatology would like to give permission to West Virginia University Department of Orthodontics to use our patient records for the above research project.

Thank your for your kind attention.

Dr. Hong HE

Professor and Chair

School of Stomatology

Wuhan University

Wuhan, China 


\section{Appendix C:}

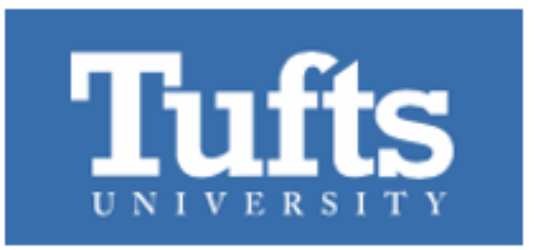

Date: September 19, 2019

Re: Data Sharing Between Universities

Whomever this may concern,

Cone-beam computed tomography (CBCT) scans of 40 individuals from a previous study carried at our institution by our research team will be shared with Dr. Peter Ngan from West Virginia University School of Dentistry. The CBCT scans will be exported into an encrypted hard-drive upon de-identification. This letter is to verify that Dr. Ngan will have the right to use the CBCT images to perform new measurements for the project titled: "Comparison of skeletal and dental changes between absolute and hybrid bone-borne maxillary expansion appliances".

Should you wish to have any questions regarding the data-sharing protocol, please contact me at:

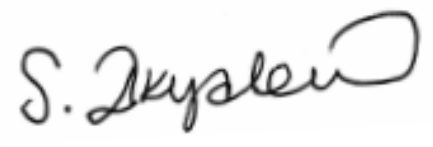

Sercan Akyalcin, D.D.S., M.S., Ph.D.

Diplomate, American Board of Orthodontics

Associate Professor, Graduate Program Director

TUFTS University School of Dental Medicine

Department of Orthodontics, No. 1142

1 Kneeland Street, Boston MA 02111

617.636.2489 tel | 617.636.2740 fax 